\title{
Immunotherapy in breast cancer patients:
}

\section{A focus on the use of the currently available biomarkers in oncology}

Carmen Criscitiello ${ }^{1,2}$, Elena Guerini-Rocco ${ }^{1,3}$, Giulia Viale ${ }^{4}$, Caterina Fumagalli ${ }^{3}$, Elham Sajjadi ${ }^{1,3}$, Konstantinos Venetis $^{1,3}$, Roberto Piciotti ${ }^{1,3}$ Marco Invernizzi ${ }^{5}$, Umberto Malapelle ${ }^{6}$, Nicola Fusco ${ }^{1,3}$

${ }^{1}$ Department of Oncology and Hemato-Oncology, University of Milan, Italy;

${ }^{2}$ Division of Early Drug Development for Innovative Therapies, IEO, European Institute of Oncology IRCCS, Milan, Italy;

${ }^{3}$ Division of Pathology, IEO, European Institute of Oncology IRCCS, Milan, Italy;

${ }^{4}$ Department of Medical Oncology, IRCCS San Raffaele Hospital, Milan, Italy;

${ }^{5}$ Physical and Rehabilitative Medicine, Department of Health Sciences, University of Eastern Piedmont, Viale Piazza D'Armi 1, Novara, Italy;

${ }^{6}$ Department of Public Health, University of Naples Federico II, Naples, Italy.

Running title: Immunotherapy biomarkers in breast cancer

CORRESPONDING AUTHOR: Nicola Fusco, MD, Division of Pathology, IEO, European Institute of Oncology IRCCS, University of Milan, Via Giuseppe Ripamonti 435, 20141 - Milan, Italy. Phone: +390294372079; Email: nicola.fusco@unimi.it. 


\begin{abstract}
Immune checkpoint inhibitors (ICls) have remarkably modified the way solid tumors are managed, including breast cancer. Unfortunately, only a relatively small number of breast cancer patients significantly respond to these treatments. To maximize the immunotherapy benefit in breast cancer, several efforts are currently being put forward for the identification of i) the best therapeutic strategy (i.e. ICI monotherapy or in association with chemotherapy, radiotherapy, or other drugs); ii) the optimal timing for administration (e.g. early/advanced stage of disease; adjuvant/neoadjuvant setting); iii) the most effective and reliable predictive biomarkers of response (e.g. tumor-infiltrating lymphocytes, programmed death-ligand 1, microsatellite instability associated with mismatch repair deficiency, and tumor mutational burden). In this article, we review the impacts and gaps in the characterization of immunerelated biomarkers raised by clinical and translational research studies with immunotherapy treatments. Particular emphasis has been put to the documented evidence of significant clinical benefits of $\mathrm{ICl}$ in different randomized clinical trials, along with preanalytical and analytical issues in predictive biomarkers pathological assessment.
\end{abstract}

KEYWORDS: breast cancer, biomarkers, immunotherapy, TILS, PD-L1, mismatch repair, microsatellite instability, tumor mutational burden. 


\section{INTRODUCTION}

Immune checkpoint inhibitors (ICls) have broadened the treatment landscape of many solid tumors, including breast cancer [1-3]. Currently approved ICls are those targeting the programmed cell death protein 1 (PD-1)/programmed death-ligand 1 (PD-L1) axis and the cytotoxic T-lymphocyte-associated protein 4 (CTLA-4) protein [4]. Regrettably, only a minority of breast cancer patients is significantly sensitive to these drugs. In these women, a remarkable number of possible ICl-containing combination strategies has been (and is being) explored, including association with radiotherapy, chemotherapy, anti-angiogenic drugs, targeted therapies, and other ICls $[5,6]$. In this multifaceted scenario, a biomarker-based approach in patients' selection for neoadjuvant or adjuvant immunotherapy is crucial to improve clinical outcomes [7].

The most studied immune-related biomarkers in breast cancer are PD-L1 expression level, distribution of tumor-infiltrating lymphocytes (TILs), high levels of microsatellite instability (MSI) associated with mismatch repair deficiency (dMMR), and degree of tumor mutational burden (TMB) [4, 8]. Despite the largest benefit has been observed in patients with PD-L1+ metastatic triple-negative breast cancers (TNBC), ICls combinations are also being studied in other subtypes and clinical settings. Current efforts focus on developing immunotherapy combinations to convert non-responders to responders, deepening those responses that do occur, and overcoming resistance. Additionally, complementary and/or surrogate biomarkers may have a role in improving the efficacy of $\mathrm{ICl}$-based regimens $[9,10]$. Novel means of mutation measurement as comprehensive genomic profiling for identifying alterations across genes are currently under investigation [11].

CTLA-4 upregulation is recognized as an important mediator of tumor immune evasion [12]. Once this antigen is exposed to cytotoxic T-lymphocyte membrane, it competes for and binds to 
B7, with a higher affinity than CD28, inhibiting the previously activated pathways. The activation of this pathway leads to the suppression of T cells and functions as a co-inhibitory signal [13]. Of note, CTLA-4 overexpression has been reported in about $50 \%$ of breast cancers [14]. Unlike in melanoma and non-small cell lung cancer $[15,16]$, however, recent clinical studies failed to demonstrate significant benefits of anti-CTLA-4 antibodies in breast cancer therapy both in terms of progression-free Survival (PFS) and overall survival (OS) [17]. The types of antibodies along with the ICls interaction mechanisms with the specific biomarkers are portrayed in Figure

1.
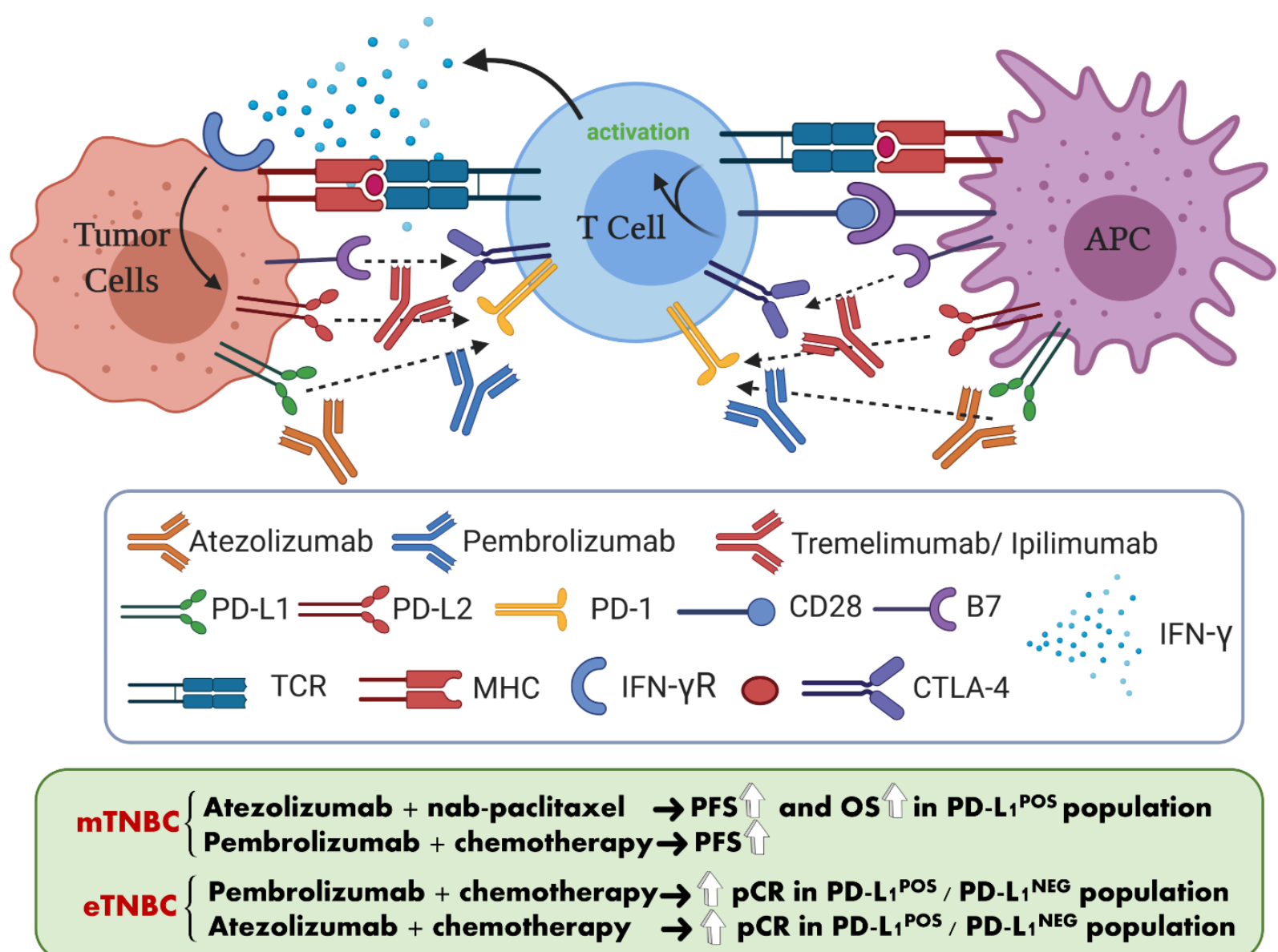

Figure 1. Immune-checkpoint inhibition in breast cancer, biomarkers, therapeutic targets, and clinical applications. Representation of T-lymphocyte activation mechanism caused by tumor-derived antigens. Tumor cells escape immune system activation by overexpressing PD-L1/2 and/or CTLA-4 ligand. ICI antibodies respectively bind to PD-L1, PD-1 and CTLA-4 and block their activation. The clinical setting of Atezolizumab and Pembrolizumab 
describe how ICI combination with chemotherapy results in patients' survival and response improvement. ICI, immune-checkpoint inhibitors; mTNBC, metastatic triple-negative breast cancer; eTNBC, early triple-negative breast cancer; TMB, tumor mutational burden; TILs, tumor-infiltrating lymphocytes; PD-1, programmed cell death protein 1; PD-L1/2, programmed death-ligand 1/2; IFNy, interferon gamma; MHC, major histocompatibility complex; TCR, T-cell receptor; CTLA-4, cytotoxic T-lymphocyte-associated protein 4; OS, overall survival; PFS, progression-free survival; pCR, pathologic complete response.

To date, the naïve vision of a single-feature-based patient selection for immunotherapy has become insufficient $[6,8]$. Indeed, in real-life practice the clinical ramifications of breast cancer management are extremely intricate. In this review article, we seek to illustrate the impacts and gaps in the characterization of immune-related biomarkers for immunotherapy prediction in breast cancer. Particular focus has been given to the reliability of currently available tools and possible drawbacks for their pathological characterization.

\section{IMMUNE CHECKPOINT BLOCKADE AND COMBINATION STRATEGIES: STATE OF THE ART}

The first approach of immunotherapy in breast cancer has been with adjuvant ICls monotherapy regimens. It has been widely demonstrated that these drugs may be active, showing objective response rates (ORR) ranging from $2.8 \%$ to $21.4 \%$, with higher benefit in TNBC, PD-L1+ tumors, and as first-line therapy [18-21]. The KEYNOTE-119 trial (NCT02555657) is the only randomized study that compares the activity of a single ICI agent (i.e. pembrolizumab, an antiPD-1 monoclonal antibody) versus single agent chemotherapy (i.e. capecitabine, eribulin, gemcitabine, or vinorelbine) for metastatic TNBC (mTNBC). The study failed to meet its primary endpoints (i.e. PFS and OS), but the clinical benefit has been reported for $\mathrm{ICl}$ administration in patients showing elevated PD-L1 expression levels (i.e. combined positive score (CPS) $\geq 20$ ). Of note, $25-30 \%$ and $60-70 \%$ of breast cancer patients experience secondary/acquired resistance and harbor primary/intrinsic resistance to ICls, respectively [22, 23]. To overcome these 
resistance phenomena, novel combinatorial treatments and alternative therapeutic strategies are currently under investigation. The most important clinical trials investigating the $\mathrm{ICl}$ efficacy in breast cancers are summarized in Table 1.

\begin{tabular}{|c|c|c|c|c|c|c|c|c|c|c|c|}
\hline NCT Number & Trial Name & $\begin{array}{c}\text { PD-L1 } \\
\text { Antibody } \\
\text { clone }\end{array}$ & $\begin{array}{l}\text { Scoring } \\
\text { system }\end{array}$ & Drug & Phase & Setting & Status & Patients & $\begin{array}{l}\text { Breast cancer } \\
\text { subtype }\end{array}$ & $\begin{array}{l}\text { Primary } \\
\text { outcome }\end{array}$ & Secondary outcome \\
\hline NCT02555657 & KEYNOTE-119 & $22 \mathrm{C} 3$ & CPS & Pembro & IIII & A & $\mathrm{Ac}(\mathrm{nr})$ & 622 & TNBC & OS & ORR, PFS, DOR, DCR, AEs \\
\hline$\overline{\text { NCT02819518 }}$ & KEYNOTE-355 & $22 \mathrm{C} 3$ & CPS & Pembro + CT & III & $A, R$ & $\mathrm{Ac}(\mathrm{nr})$ & 882 & TNBC & AEs, PFS, OS & ORR, DOR, DCR \\
\hline NCT03036488 & KEYNOTE-522 & $22 \mathrm{C} 3$ & CPS & Pembro + CT & III & A & $\mathrm{Ac}(\mathrm{nr})$ & 1,174 & TNBC & $\mathrm{pCR}, \mathrm{EFS}$ & pCR, EFS, OS, AEs, \\
\hline NCT02447003 & KEYNOTE-086 & $22 \mathrm{C} 3$ & CPS & Pembro & $\|$ & A & $\mathrm{C}$ & 254 & TNBC & ORR, AES & DOR, DCR, PFS, OS \\
\hline NCT01848834 & KEYNOTE-012 & $22 \mathrm{C} 3$ & CPS & Pembro & $i$ & A & c & 297 & TNBC & $\mathrm{AEs}, \mathrm{ORR}$ & ORR \\
\hline NCT02628067 & KEYNOTE-158 & $22 \mathrm{C} 3$ & CPS & Pembro & ॥ & A & $\mathrm{Re}$ & 1,595 & Any & ORR & DOR, PFS, OS \\
\hline NCT02425891 & IMpassion130 & SP142 & IC & Atezo + Nab-Pacl & III & A & $\mathrm{Ac}(\mathrm{nr})$ & 900 & TNBC & PFS, OS & $C R, P R, D O R, T T D, A E s, A T A s$ \\
\hline NCT03125902 & IMpassion131 & SP142 & IC & Atezo + Pacl & III & A & $\operatorname{Ac}(n r)$ & 600 & TNBC & PFS & OS, PA, TTD, ORR, DOR, AEs, C- \\
\hline NCT03371017 & IMpassion132 & SP142 & IC & Atezo + CT & IIII & $\mathrm{R}$ & $\mathrm{Re}$ & 572 & TNBC & os & PA, PFS, ORR, DOR, CBR, C-DoR, T \\
\hline NCT03197935 & IMpassion031 & SP142 & IC & Atezo + CT & III & $\mathrm{E}$ & $\mathrm{Ac}(\mathrm{nr})$ & 324 & TNBC & $\mathrm{pCR}$ & EFS, DFS, OS, ADAs \\
\hline NCT02685059 & GeparNuevo & SP263 & IC & MEDI4736 (Anti PD-L1) + CT & II & $\mathrm{E}$ & Un & 174 & TNBC & $\mathrm{pCR}$ & PCR, CR, AEs, OS \\
\hline NCT02620280 & NeoTRIPaPDL1 & SP142 & IC & Atezo + Carbo + Nab-Pacl & IIII & $\mathrm{E}, \mathrm{A}$ & $\mathrm{Ac}(\mathrm{nr})$ & 278 & IDBC & EFS & PCR, COR, DEFS \\
\hline NCT02129556 & PANACEA & $22 \mathrm{C} 3$ & CPS & MK-3475 + Trastu & I/II & A & c & 58 & HER2 $^{+}$ & DLT, ORR & DOR, TTP, DCR, PFS, OS \\
\hline NCT02924883 & KATE2 & SP142 & IC & Atezo + Trastu emtansine & " & A & c & 202 & HER2 ${ }^{+}$ & PFS, AEs & OS, OR, ATAS \\
\hline NCT02489448 & $\mathrm{N} / \mathrm{A}$ & SP263 & ${ }_{I C}$ & $\begin{array}{l}\text { MEDI4736 (Anti PD-L1) + } \\
\text { Nab-Pacl + CT }\end{array}$ & $1 / 11$ & $\mathrm{E}$ & $\begin{array}{l}\text { Suspended due } \\
\text { to COVID-19 }\end{array}$ & 71 & TNBC & $\mathrm{pCR}$ & Safety and Toxicity \\
\hline NCT03199885 & N/A & N/A & N/A & Atezo + Pacl + Trastu + Pertu & III & A & $\mathrm{Re}$ & 600 & $\mathrm{HER}^{+}{ }^{+}$ & PFS & OS, OOR, AEs \\
\hline NCT03051659 & $\mathrm{N} / \mathrm{A}$ & $22 \mathrm{C} 3$ & MPS & Pembro + EM & $\|$ & A & $\mathrm{Ac}(\mathrm{nr})$ & 88 & $\mathrm{HR}^{+}$ & PFS & ORR, OS, IRR, DOR, CBR \\
\hline
\end{tabular}

Table 1. Ongoing and recently completed clinical trials using immune checkpoint inhibitors (ICI) alone or in combination in breast cancer patients based on PD-L1 status.

Abbreviations: PD-L1, programmed death ligand 1; CPS, combined positive score; IC, immune cell; MPS, modified proportion score; A, advanced/metastatic; R, recurrent; E, early; Ac, active; nr, not recruiting; Re, Recruiting; Un, Unknown; C, completed; Pembro, pembrolizumab; Atezo, Atezolizumab; Pacl, Paclitaxel; CT, chemotherapy; Carbo, Carboplatin; EM, Eribulin Mesylate; Trastu, Trastuzumab; Pertu, Pertuzumab; TNBC, Triple-Negative Breast Cancer; IDBC, Invasive ductal breast carcinoma; HR, Hormone receptor; HER2, Human epidermal growth factor receptor 2; OS, Overall survival; PFS, Progression-free survival; AEs, adverse events; pCR, pathologic complete response; EFS, Event-fee survival; DLT, Dose-limiting toxicity; ORR, objective response rate; DOR, Duration of response; DCR, disease control rate; CR, Complete response; PR, Partial response; TTD, Time to deterioration; ATAs, Antitherapeutic antibodies; PA, Participants alive; C-DoR, Duration of confirmed response; CBR, Clinical benefit rate; ADAs, Anti-drug antibodies; COR, Clinical objective response; DEFS, Distant event free survival; IRR, Immune response rate; OOR, Overall objective response; N/A, Not available. Information has been obtained from clinicaltrials.gov.

\section{Anti-PD-L1 immunotherapy in advanced/metastatic settings}

To date, the only immunotherapy regimen approved in breast cancer patients is the combination of the anti-PD-L1 monoclonal antibody atezolizumab and nanoparticle albumin-bound (nab)paclitaxel as first-line treatment for PD-L1+ $\mathrm{mTNBC}$ [24]. This approval followed the results of the IMpassion130 (NCT02425891), a phase III randomized trial that enrolled patients with treatment-naïve mTNBC to receive either atezolizumab plus nab-paclitaxel or nab-paclitaxel and 
placebo [24]. OS and PFS were co-primary endpoints of the study. The trial had a hierarchical statistical design, requiring benefit in the intent-to-treat (ITT) population to formally test the effect in subgroups by PD-L1 status. In this study, PD-L1 was assessed by immunohistochemistry (IHC) using the VENTANA PD-L1 (SP142) Assay (Roche). The positivity was defined when PDL1 was expressed in $\geq 1 \%$ of immune cells (IC) [24]. This study showed that the addition of atezolizumab to nab-paclitaxel significantly improves PFS in both the ITT population and the PD-L1+ population. The OS analysis in the ITT population was negative but suggested a clinically meaningful OS benefit with atezolizumab plus nab-paclitaxel in patients with PD-L1 IC+ disease, leading to a 7 -month OS improvement $[24,25]$. These results led the United States Food and Drug Administration (FDA) and the European Medicines Agency (EMA) to approve the combination of atezolizumab plus nab-paclitaxel in this setting. The IMpassion131 trial (NCT03125902) investigated the combination of atezolizumab and paclitaxel vs. paclitaxel alone as first-line therapy for patients with mTNBC. The results of this study have been recently presented and showed neither a PFS nor OS advantage when atezolizumab was added in both PD-L1 ${ }^{+}$and ITT populations. The ongoing randomized Phase III IMpassion132 trial (NCT03371017) is evaluating the efficacy of first-line atezolizumab in combination with chemotherapy vs. chemotherapy alone for inoperable locally advanced/mTNBC relapsing within 1 year after standard (neo)adjuvant anthracycline and taxane chemotherapy [26, 27].

\section{Anti-PD-1 immunotherapy in advanced/metastatic settings}

The KEYNOTE-355 study has recently shown a benefit with the combination of first-line pembrolizumab and chemotherapy in previously untreated mTNBC (NCT02819518) [28]. In this phase III trial, patients were randomized to receive chemotherapy (i.e. taxane or carboplatin/gemcitabine) with placebo or chemotherapy plus pembrolizumab. In this study, PDL1 was assessed by using the PD-L1 IHC 22C3 pharmDx assay (Agilent) [29]. Patients were stratified for PD-L1 expression (CPS $\geq 1$ vs CPS $<1$ ). The combination of chemotherapy and 
pembrolizumab significantly improved PFS compared with chemotherapy alone in patients with CPS $\geq 10$, whereas patients with a CPS $<10$ did not seem to benefit from the addition of pembrolizumab to chemotherapy. These findings suggest a role for the addition of pembrolizumab to standard chemotherapy for the first-line treatment of mTNBC [28]. The estimated study completion date of the KEYNOTE-355 study is January 2022.

\section{Immune-checkpoint inhibition in early stage}

Metastatic breast cancer is commonly not inflamed due to the immune escape mechanisms occurring during the disease progression [30-33]. Hence, an important point is whether ICls should be given as early as possible, thus including neoadjuvant therapy, in the course of the disease. Two recently presented trials combining ICls with chemotherapy in early-stage TNBC have shown promising results. The KEYNOTE-522 (NCT03036488) trial randomized patients with TNBC suitable to neoadjuvant treatment to receive chemotherapy with carboplatin/paclitaxel followed by anthracycline/cyclophosphamide with or without pembrolizumab as neoadjuvant, followed by surgery, plus nine more cycles of pembrolizumab or placebo in the adjuvant setting [34]. In this trial, the addition of pembrolizumab led to a statistically significant increase in pathologic complete response $(\mathrm{pCR})$ rate, both in ITT population (51.2\% vs $64.8 \%, \quad \mathrm{p}=0.00055)$ and $\mathrm{PD}-\mathrm{L} 1^{+}$population $(54.9 \%$ vs $68.9 \%$ ). Interestingly, pembrolizumab improved pCR rate also in patients with PD-L1' tumors (30.3\% vs 45.3\%) [34]. This study has also shown a positive trend in terms of event-free survival (EFS), although data are not mature yet (hazard ratio $(\mathrm{HR}), 0.63 ; 95 \% \mathrm{Cl}, 0.43-0.93)$. An important neoadjuvant trial is the IMpassion031, which randomized patients with TNBC to receive chemotherapy with nab-paclitaxel followed by anthracycline/cyclophosphamide with atezolizumab or placebo as neoadjuvant, followed by surgery, plus 11 more cycles of atezolizumab or placebo continued in the adjuvant setting. The co-primary endpoint of the study, pCR in the ITT population, is significantly in favor of adding atezolizumab to 
chemotherapy $(41.1 \%$ vs $57.6 \%, P=0.0044)$. The other co-primary endpoint, $\mathrm{PCR}$ in the PD$\mathrm{L} 1^{+}$population, is also significant in favor of adding atezolizumab (49.3\% vs $68.8 \%$ ). Here again, the addition of atezolizumab increased the PCR rate also in the PD-L1- population (34.4\% vs 47.7\%). At subgroup analyses, both in KEYNOTE-522 and IMpassion031 trials, patients with node-negative disease seem to derive less benefit with such combination.

\section{Studies with negative results}

Despite the above-mentioned significant results, research of ICls in breast cancer is paved of negative studies. The GeparNuevo trial (NCT02685059), a randomized phase II study investigating durvalumab in addition to an anthracycline taxane-based neoadjuvant therapy in early TNBC, failed to demonstrate an increased $\mathrm{pCR}$ rate in the overall population (A randomized phase II study investigating durvalumab in addition to an anthracycline taxanebased neoadjuvant therapy in early triple-negative breast cancer: clinical results and biomarker analysis of GeparNuevo study) [35]. Improved pCR rate was highlighted in the subgroup treated with durvalumab started two weeks before chemotherapy. However, this analysis was underpowered for significance testing. The NeoTRIPaPDL1 trial (NCT02620280) explored the addition of atezolizumab to neoadjuvant carboplatin/nab-paclitaxel followed by surgery and then adjuvant anthracycline/cyclophosphamide [36]. This study did not report significant differences in $\mathrm{pCR}$ rates among patients who did or did not receive atezolizumab (43.5\% vs 40.8\%; $\mathrm{P}=.66$ ). However, it is worth reminding that pCR was a secondary endpoint of the study, while EFS data, which was the primary endpoint, is still awaited [36].

\section{Immunotherapy in other breast cancer subtypes}

Although ICls administration has been predominantly studied in TNBC, some studies have been carried out also in other metastatic breast cancer subtypes. In hormone receptor $(\mathrm{HR})^{+} / \mathrm{HER}^{-}$ breast cancer patients, the efficacy of ICls as monotherapy seems to be very limited $[37,38]$. 
Recently, a multicenter randomized phase II trial evaluated the addition of pembrolizumab to eribulin vs. eribulin alone [39]. In this study, patients with previously treated $\mathrm{HR}^{+} / \mathrm{HER} 2$ - disease did not benefit from the addition of $\mathrm{ICI}$ to chemotherapy. Combinations of ICls with other agents (e.g. CDK4/6 inhibitors) have also been explored with limited results $[40,41]$. In the HER2 ${ }^{+}$ subtype, the combination of an ICI plus an anti-HER2 agent has been firstly assessed in the PANACEA trial [42]. This study included patients with metastatic $\mathrm{HER}^{+}$breast cancer who progressed after trastuzumab-based therapy. These patients, regardless of the PD-L1 status, received a combination of pembrolizumab and trastuzumab. An ORR of $15 \%$ was highlighted among patients with PD-L1+ tumors, whereas no responses were observed among patients with PD-L1+ tumors. More recently, the KATE2 study evaluated whether the addition of atezolizumab to trastuzumab emtansine (T-DM1) improved efficacy in patients progressed on previous therapy with trastuzumab and a taxane [43]. The study failed to demonstrate a PFS benefit in the ITT population [43]. However, a trend towards improved OS has been observed in patients with PD-L1+ tumors treated in the atezolizumab arm [43]. Currently, a multicenter randomized phase III trial is going to test the efficacy of first-line trastuzumab, pertuzumab, and paclitaxel with or without atezolizumab (NCT03199885) in the setting of HER2+ breast cancers.

\section{Small-molecule immune checkpoint inhibitors}

Albeit the majority of the ICls are monoclonal antibodies, small molecule immuno-oncology inhibitors are actively being pursued by pharmaceutical companies and research groups [4446]. Most of these low-molecular-weight compounds have been designed for inhibiting the PD1/PD-L1 interaction overcoming several shortcomings of monoclonal antibodies (e.g. long halflife, adverse effects, low permeability, costs of production and treatment) [47, 48]. Recent studies implemented biochemical and cell-based bioassays to determine the binding, activity, and cytotoxicity of different inhibitors such as BMS-1001, BMS-1166, MS-103, BMS-142 and Aurigene-1 $[49,50]$. Most of these compounds are capable of binding specifically to PD-L1, 
while they show increased inhibitory activity of the PD-1/PD-L1 interaction and low toxicity levels $[49,50]$. Additionally, Konieczny et al. reported the development of a novel compound that is more potent and smaller in size compared to others reported in the literature, with improved solubility and nontoxic activity to cells even at high concentrations [51]. CA-170 is an orally available small molecule that directly targets the PD-L1/PD-L2 and V-domain Ig suppressor of T cell activation (VISTA) immune checkpoints and results in activation of T cell proliferation and cytokine production [52]. The safety and pharmacokinetic profile of this small molecule has been tested in a recently completed phase I clinical study involving patients with advanced malignant tumors including TNBC, mesothelioma, melanoma, non-small cell lung cancer, renal cell carcinoma, Hodgkin lymphoma, head and neck cancer, colorectal cancer, gastric cancer, bladder cancer, and ovarian cancer (NCT02812875) [53]. Lessons learned from the development of these agents can accelerate the development of next-generation inhibitors to optimize the therapeutic index, overcome drug resistance, and establish combination therapies. However, further translational and clinical studies are warranted to define whether women with breast cancer would benefit of these drugs.

\section{CLINICOPATHOLOGIC FEATURES RELATED TO IMMUNOTHERAPY RESPONSE}

Among breast cancer subtypes, TNBC is usually characterized by higher TILs, PD-L1 expression, and high TMB, suggesting a potential role for immunotherapy [54]. However, TNBCs are extremely heterogeneous and encompass a multitude of tumor types with different morphology, molecular features, immunogenicity, and responses to therapies [55-57]. Surrogate and/or complementary biomarkers, coupled with tumor-specific guidelines and testing methods, might potentially improve the extremely diffucult task of breast cancer patients selection for immunotherapy. The available immune-related biomarkers for breast cancers, and their current prognostic and predictive applications, are shown in Figure 2. 

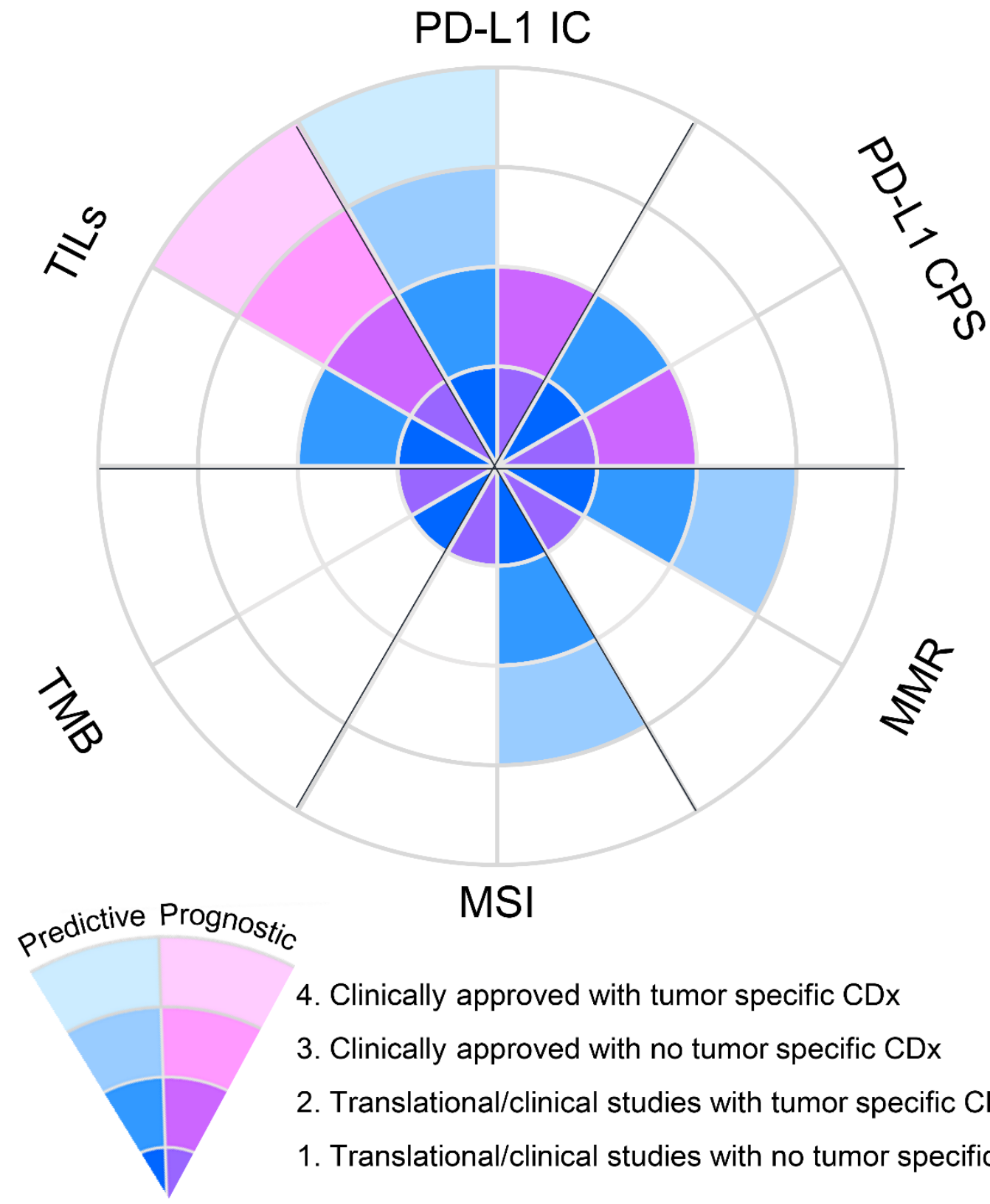

4. Clinically approved with tumor specific CDx

3. Clinically approved with no tumor specific CDx

2. Translational/clinical studies with tumor specific CDx

1. Translational/clinical studies with no tumor specific CDx

Figure 2. Schematic representation of the main prognostic and predictive biomarkers along with their clinical significance in breast cancer immuno-oncology. Each circle represents the possible application of the various biomarkers in clinical practice, as depicted in the legend. CDx, companion diagnostic test; PD-L1, programmed cell death ligand 1; IC, immune cell; CPS, combined positive score; MMR, mismatch repair; TMB, tumor mutational burden; MSI, microsatellite instability; TILs, tumor-infiltrating lymphocytes. 


\section{Tumor-infiltrating lymphocytes (TILs)}

TILs are mononuclear immune cells discovered within tumor tissue in most types of solid tumors, including breast cancer. They are mainly composed of cytotoxic $\mathrm{CD} 8^{+} \mathrm{T}$ cells, helper $\mathrm{CD}^{+} \mathrm{T}$ cells, and natural killer (NK) cells [58]. Cancer-specific mutations and/or neoantigens released in the microenvironment by damaged cancer cells may activate the TILs anti-tumor immune response [59-62]. Most of the studies assessed TILs on a single hematoxylin and eosin (H\&E)-stained tumor section, dividing the stromal and intratumoral compartments. Intratumoral TILs (iTILs) directly infiltrate tumor cell nests, whereas stromal TILs (sTILs) are found within the stromal tissue of the tumor. The latter are considered a more reliable biomarker in predicting response to therapy and patient outcome [63-65]. Both compartments may comprise a combination of different lymphocyte subtypes, with a predominant T-cell population. International cooperative efforts are ongoing to maximize reproducibility of this putative prognostic and predictive biomarker [63].

TILs have an established prognostic role in TNBC and HER2 ${ }^{+}$early/locally advanced breast cancer patients. In these subtypes, a correlation between an increased number of sTILs and outcomes (disease-free survival (DFS) and OS) was demonstrated in multiple retrospectiveprospective studies [66-71]. Data on the correlation between TILs and response to immunotherapy were investigated in a few recent clinical trials. In the mTNBC, higher TILs concentrations were associated with improved response in patients treated with pembrolizumab monotherapy in the phase II KEYNOTE-086 study [72, 73]. High TILs levels were also associated with significant improvement in ORR (Odds ratio OR) 1.26, 95\% $\mathrm{Cl}$ 1.03- 1.55, $\mathrm{p}=0.01)$ and disease control rate $(\mathrm{DCR})(\mathrm{OR} 1.22,95 \% \mathrm{Cl} 1.02-1.46, \mathrm{p}=0.01)$. In the PANACEA phase $\mathrm{lb} / \mathrm{ll}$ trial, 58 metastatic HER2 ${ }^{+}$breast cancer patients received a combination of trastuzumab and pembrolizumab; a significantly greater lymphocytic infiltration was observed in responders and patients with longer disease control [74]. In a systematic review and meta- 
analysis investigating predictive factors of ICls efficacy in metastatic breast cancer, 27 studies with 1746 patients were included [75]. Despite only a few trials reported TILs evaluation, TILs $\geq$ $5 \%(O R=2.53, p=0.002)$ and high infiltrated $C D 8^{+}$T-cell level $(O R=4.33, p=0.006)$ emerged as predictors of immune checkpoint therapy response, in terms of ORR. Of note, in a phase I/II trial (NCT02489448) the safety and efficacy of concurrent durvalumab with weekly nabpaclitaxel followed by dose-dense doxorubicin and cyclophosphamide as neoadjuvant therapy for stage I-III TNBC were investigated [76]. TILs counts were available for 52 out of 57 patients; no significant differences in response to therapy were observed according to TILs value. This may be partly due to the complexity of the immune microenvironment, which is shaped by competing for co-stimulatory and co-inhibitory signals [77]. Taken together, despite their significant prognostic role, TILs role as an independent predictive factor for immunotherapy is still not ready for prime time.

\section{Programmed death-ligand 1 (PD-L1)}

The interplay between PD-1 and its agonist PD-L1 could serve as an escape mechanism for tumors to evade antigen-specific T-cell immunologic responses [78, 79]. In breast cancer, PDL1 expression is often associated with poor clinicopathologic features, high TILs count, and triple-negative phenotype (Figure 3) [80, 81].

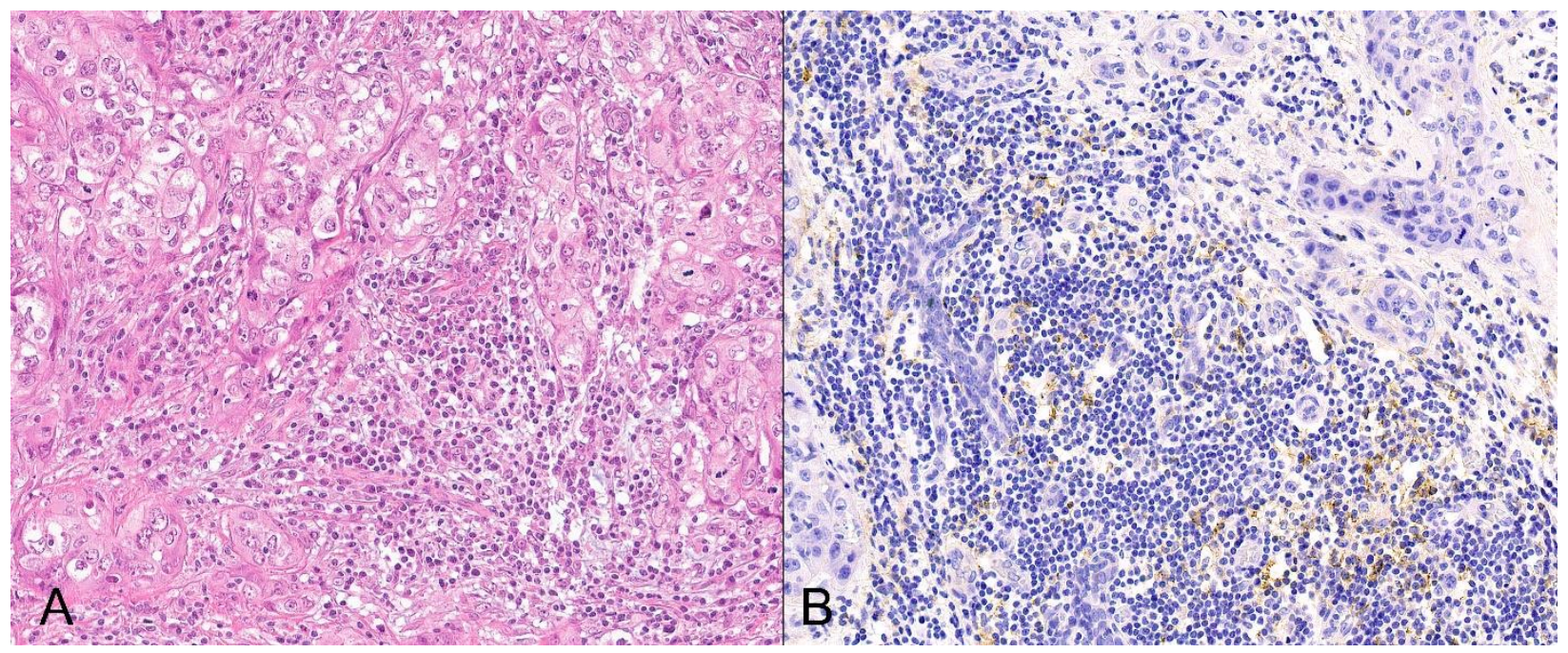


Figure 3. Representative micrographs showing a case of poorly differentiated infiltrating triple-negative breast cancer of no special histological type. This tumor showed a prominent stromal infiltrate of immune cells, being classified as TILs-high (A). Given that both tumor cells and TILs showed PD-L1 immunoreactivity, albeit with different degrees of staining intensity (i.e. faint in tumor cells, mild-moderate in TILs), the combined positive score (CPS) was scored $>20(B)$. Original magnification, $200 x$.

The PD-1/PD-L1 axis is considered a promising immunotherapeutic target in several solid tumors [82]. PD-1/PD-L1 blockage leads to the activation of $\mathrm{T}$ cells that can recognize and attack cancer cells $[83,84]$. So far, PD-L1+ and treatment-naïve TNBC patients have been the most suitable candidates for ICI therapy in breast cancer [85]. Preliminary evidence regarding the clinical activity of pembrolizumab was firstly reported in the KEYNOTE-012 trial (NCT01848834). This study included previously treated, advanced TNBC patients showing an ORR of $18.5 \%$, and a median time to response of 17.9 weeks (range, 7.3 to 32.4 weeks) [18]. Subsequently, the phase II KEYNOTE-086 (ㄷT02447003) examined the efficacy and safety of pembrolizumab monotherapy in two cohorts of patients. The first cohort included patients exposed to one or more prior lines of systemic treatment for metastatic disease regardless of PD-L1 expression, while the other cohort involved PD-L1+ patients with non-systemic anticancer therapy $[20,73]$. The PD-L1+ cohort showed an ORR of $23 \%(95 \% \mathrm{Cl} 14-36)$. This suggested a promising antitumor activity of pembrolizumab as first-line therapy for PD-L1+, mTNBC [5, 20, 73]. Antibodies for PD-L1 assessment by IHC have different interpretation guidelines, which lead to the identification of different patient populations [86]. A post hoc analysis of IMpassion130 assessed the analytical concordance of PD-L1 evaluation by SP142, SP263 (VENTANA), and PD-L1 22C3 (Dako) IHC assays [87]. PD-L1 positivity was considered as, IC $\geq 1 \%$ for SP142 and SP263 assays, and CPS $\geq 1$ for the 22C3 assay. These findings showed that the 22C3 and SP263 assays identified more patients with PD-L1+ tumors (81\% and 75\% respectively) compared to SP-142 (46\%) [87]. However, the absolute benefit for the addition of atezolizumab for the samples that were only positive with 22C3 assay (PFS: 1.7 months) or SP- 
263 (PFS: 1.6 months) was considered different in comparison with those that were only positive for SP-142 (PFS: 4.2 months) [86]. Accordingly, the SP-142 antibody showed the greatest clinical benefit in the TNBC, PD-L1+ patients.

\section{Mismatch repair and microsatellite instability}

The MMR system recognizes and corrects ribonucleotide misincorporation errors generated during DNA replication and recombination, preserving the overall replication fidelity and genome stability $[88,89]$. MMR deficiency (dMMR) may be generated due to mutations and/or epigenetic silencing of MMR genes, potentially leading to MSI, a phenotype characterized by alterations in the length of microsatellite regions $[90,91]$. It has been observed that dMMR tumors harbor several mutations in cancer-related genes resulting in high neoantigen formation and subsequent T-cell recruitment, making these patients likely sensitive to ICls [92, 93]. Relying on this rationale, the FDA granted the tissue-agnostic approval of pembrolizumab in dMMR or MSIhigh solid tumors [94]. Although this approval is reasonable across different types of cancer where these biomarkers are well-validated [95, 96], in breast cancer, further investigation of the MMR and MSI status is warranted. MMR deficiency shows a relatively low frequency in breast cancer, being present in approximately $2 \%$ of cases. However, this is a controversial matter due to the lack of companion diagnostic $(C D x)$ tests and/or tumor-specific guidelines for MMR analysis [9, 97-101]. Most of the protocols that have been employed to date are locally developed using different methods such as the sequencing of microsatellite markers, nextgeneration sequencing (NGS), and IHC for the four MMR proteins. A recent study demonstrated that $\mathrm{dMMR}$ can be used as a prognostic and likely predictive biomarker, but without being interchangeable with MSI as in other tumor types [98]. Additionally, a case study of a woman with metastatic, ER+ ${ }^{+}$, HER2- breast cancer, showed durable complete remission after treatment with pembrolizumab [102]. Although dMMR cases are infrequent in breast cancer, there is an urgent need to identify and select even that fairly low proportion of patients who could benefit 
from immunotherapy. To accomplish this goal a standardization of MMR analysis with tumorspecific guidelines would be required. In this respect, the phosphatase and tensin homolog (PTEN) was recently proposed as a complementary biomarker for MMR testing in breast cancer [9]. Indeed, this gene is not only involved in cell growth, proliferation, and survival, but it is also implicated in the modulation of the DNA damage response and in tumor immune microenvironment modeling [10]. Hence, PTEN expression analysis can be employed to identify MMR-proficient breast cancers, thus overcoming the lack of overlapping between MMR IHC and MSI analyses [9]. Additional clinical trials and prospective translational research studies are needed to provide reliable results for MMR testing in the selection of breast cancer patients for immunotherapy.

\section{Tumor mutational burden}

The term TMB refers to the absolute number of somatic mutations per mega-base (mut/Mb) arising in tumor-coding regions [103]. Given that patients with a high-TMB (hTMB) are more prone to achieve clinical benefit from $\mathrm{ICl}$ treatment, this biomarker has been proposed in predictive settings $[104,105]$. Despite not all mutations result in immunogenic neoantigens, the higher is TMB the greater is the probability of tumor neoantigen production and, therefore, the immune triggering [106]. Breast cancers display intermediate levels of mutational load [107], with a significantly higher median TMB in TNBC compared to other receptor subtypes (TNBC> $\mathrm{HER}^{+}>\mathrm{ER}^{+} / \mathrm{HER2}{ }^{-}$[ [108]. Although debated, high TMB value (>10mut/Mb) are observed in less than $5 \%$ of breast cancers, with prevalence varying according to breast cancer subtype $[108,109]$.

The correlation between TMB levels and the expression of immune-related biomarkers is still controversial. In pooled analyses of different cancer types as well as in breast cancer, a positive association of TMB and TILs was observed [59, 109]. Additional studies failed to detect this 
correlation in TNBC [110, 111]. Furthermore, unlike in other solid tumors [112], no significant association between PD-L1 positivity and hTMB was observed in breast cancer [113, 114]. Interestingly, a hTMB status is recurrent in breast cancers with DNA repair deficiency due to alterations in the MMR pathway. Mutations in replicative DNA polymerases (e.g. POLE and $P O L D 1$ ), and deficit in the homologous recombination repair system occurrence are also associated to $\mathrm{hTMB}[108,109,115,116]$. Moreover, an association between misregulation of DNA-mutating enzymes activity (i.e. APOBECs) and a hypermutator phenotype has been identified in breast cancer $[108,117]$. There is recent evidence that TMB levels may double in the metastasis compared to the primary tumor in breast cancer patients, maybe due to treatment-associated selective pressure $[108,110,114,117]$. Moreover, hTMB level is usually observed in older breast cancer patients $[110,114]$. Among patients with mTNBC treated with ICl, hTMB was significantly associated with longer survival independently of PD-L1 status, while TMB predicted $\mathrm{pCR}$ after neoadjuvant ICI in early TNBC $[110,118]$. Remarkably, TMB levels detected in circulating tumor DNA seem to mirror those observed at the tissue level, making TMB testing on liquid biopsy a promising and less invasive strategy [119].

Despite the potential clinical application, TMB role in breast cancer immuno-oncology still requires further studies. Hence, different pre-analytical and analytical variables can dramatically affect its measurement and reproducibility. Several studies suggested that TMB assessment using targeted NGS panels, instead of whole exome sequencing (WES), is more reliable [120]. Regrettably, the heterogeneity of the possible targeted panels may affect TMB counts. Another crucial question regards the definition of a cutoff value to identify hTMB and therefore patients that could benefit from immunotherapy. TMB is a continuous variable and placing a threshold may be challenging. Different cutoffs values (as $\geq 10,16,20$ mut/Mb detected by F1CDx panel) have been proposed by several groups to reach the best accuracy in identifying $\mathrm{ICI}$ responsive patients [121-123]. In June 2020 the FDA approved a cutoff of $\geq 10 \mathrm{mut} / \mathrm{Mb}$, measured by 
F1CDx, for labeling hTMB in solid tumors, predictive of pembrolizumab response, based on the KEYNOTE-158 clinical trial [124]. Regrettably, no additional guidelines using other TMB tests and/or different ICI protocols are currently available [125]. Notably, the European Society for Medical Oncology (ESMO) has recently recommended TMB testing in several tumors to predict pembrolizumab response but not yet in breast cancer [126].

\section{WHAT SAMPLE TO TEST AND WHICH ASSAY TO USE:}

\section{A STILL UNADDRESSED DILEMMA}

The evaluation of PD-L1 expression using IHC on tumor tissue sections is the most studied biomarker for immunotherapy in different tumor types $[4,62,127,128]$. In this respect, a variety of antibody clones and scoring systems is currently available. Similar analytical performance has been reported for SP263, 22C3 and 28-8 antibodies considering tumor cells expression; while a lower number of cells are stained using SP142 assay [129, 130]. However, variability was observed across the four assays evaluating immune cell expression [129]. In the IMpassion130 trial, PD-L1 expression using the SP142 antibody clone predicted the benefit from the combination of atezolizumab and nab-paclitaxel [131]. In a retrospective analysis of the trial population, a higher number of PD-L1+ tumors have been identified using Dako 22C3, and SP263 as compared to SP142 assay. However, small absolute benefit and no median OS differences were seen among patients with PD- L1+ tumors as identified only by $22 \mathrm{C} 3$ or SP263 antibodies [86, 87]. VENTANA PD-L1 (SP142) IHC assay was the only approved companion diagnostic test for atezolizumab using the tumor-infiltrating IC score with a cut-off of $1 \%$ [132]. IC score is defined as the proportion of tumor area occupied by PD- $L 1^{+}$immune cells located in the intratumoral and contiguous peritumoral stroma; tumors are considered PD-L1+ showing $\geq 1 \%$ IC score [133-135]. 
Laboratory-developed or commercial microsatellite markers PCR-based tests are used for the identification of MSI. The analysis of MMR proteins expression (i.e. MLH1, PMS2, MSH2 and MSH6) using IHC has been performed to ascertain dMMR tumors [88, 97]. Moreover, NGSbased approaches have been increasingly adopted to assess MSI in the context of comprehensive genomic profiling [136]. Most methods have been largely validated for specific tumor types (i.e. colorectal cancers), demonstrating good concordance between MSI and MMR status [137]. Indeed, for patients with sporadic cancers that fall in the Lynch syndromeassociated tumor spectrum, IHC MMR protein evaluation is recommended as the first-choice method followed by MSI PCR-based testing for cases with equivocal or indeterminate results [138]. However, no companion diagnostic test and/or tumor-specific guidelines are currently available for MSI/MMR testing and few data have been reported about the performance of these different methods in breast cancers $[98,136]$.

Given the immunological heterogeneity between primary and metastatic cancer and the dynamic nature of tumor-immune interplay [33, 128], samples from metastatic/relapse breast cancer may be required for the assessment of immunotherapy biomarkers. In the metastatic setting, a biopsy of an accessible metastatic lesion is currently recommended for patients with advanced breast cancers, although samples from primary tumors are considered acceptable for the analysis of PD-L1 and/or MSI/MMR [134, 135]. Core biopsy tissue specimens should be managed according to standard laboratory procedures to have sufficient material for diagnostic purposes, to reassess biological markers and, when indicated, to test other predictive factors. Although cytology and bone metastasis samples are adequate for DNA extraction and molecular profiling, they are currently considered suboptimal for PD-L1 analysis [135, 139]. The IC score with VENTANA PD-L1 (SP142) Assay should be performed on a tissue sample with at least 50 viable tumor cells [135]. Pre-analytical factors that may affect both the quality of DNA and immunostaining include the time of tissue fixation, type of fixative, and storage condition of 
the tissue blocks [135, 140]. In some tumors, liquid biopsy has been shown as a valid alternative for biomarkers analysis especially when tissue specimens are insufficient, or tissue biopsy is not feasible/available [141]. TMB and MSI can also be assessed on cfDNA using broad NGS panels [142, 143]. Moreover, analysis of PD-L1 expression on circulating tumor cells and PD-L1 quantification in plasma sample have been reported, with promising results [144]. However, the implementation and the role of these tests in the clinical setting still require further investigation.

\section{FINAL REMARKS}

Immunotherapy has changed the way we treat a subset of patients diagnosed with advanced TNBC. The combination of atezolizumab and nab-paclitaxel is currently the standard first-line therapy in patients with metastatic TNBC who have a PD-L1-positive disease. Although the current approval is limited to a minority of patients, other treatment modalities are showing promising results and might become concrete options in the near future, thus expanding the potential applicability of immunotherapy in breast cancer. Several clinical trials are testing in mTNBC combinations of PD-1/PD-L1 inhibitors and different agents including radiation therapy, targeted agents, and other immunotherapy agents. Furthermore, there is available evidence suggesting that radiation therapy may trigger an immune response through interferon signaling, thus causing immunogenic cell death [145-147]. The activation of dendritic cell and their interaction with T cells may induce the so-called abscopal effect, which is represented by the regression of metastases distant from the irradiated site [147]. Among targeted agents that may be combined with PD-1/PD-L1 inhibitors, particular interest relies on PARP inhibitors, as they have been recently approved for patients with BRCA1/BRCA2 germline mutations. Such combination is also based on a solid scientific rationale that shows how BRCA-mutated tumors are more immunogenic [148-150]. PARP inhibitors trigger interferon signaling and antitumor 
immunity response, through the activation of the STING pathway, thus leading to CD8+ T cells infiltration into the tumor microenvironment [150]. The combination of PARP inhibitors and ICls seems to play a synergistic activity, as seen in clinics. [151, 152] Moreover, immunotherapy agents other than PD-1 or PD-L1 inhibitors have demonstrated promising synergistic activity in breast cancer. As an example, we may cite the lymphocyte activation gene-3 (LAG-3), which acts synergistically with PD-1 to ensure immune homeostasis, through modulation of cytokine secretion and subsequent lymphocyte activation inhibition [153]. Durable responses have been documented in patients with advanced TNBC, who have been treated - whiten a phase I trial with a combination of spartalizumab (a monoclonal antibody blocking interaction of PD-1 with PD-L1 and PD-L2) and LAG525, a monoclonal antibody blocking binding of LAG-3 to major histocompatibility complex class II [154]. More recently, we have also witnessed the benefit - in terms of increased $\mathrm{pCR}$ rate - provided by the addition of PD-1/PD-L1 inhibitors to standard treatment in the neoadjuvant setting; however, survival data are still immature [155].

These data, combined with the evidence that immune escape progressively augments while the disease advances, may lead us to think whether anticipating immunotherapy as earlier as possible in the course of the disease would be more beneficial $[30-33,156]$. On the other hand, when we talk about immunotherapy, especially in the curative setting, we cannot forget the potential immune-related adverse events, which require an integrated approach for their prevention and management. The way to optimize immunotherapy benefits in breast cancer is still long. Correlative studies in patients treated with immunotherapy are needed to select the best strategies for further development as well as to identify biomarkers able to expand the group of patients more likely to benefit. 


\section{Consent for Publication}

Not applicable.

\section{Funding}

None.

\section{Conflict of Interest}

C.C. has received honoraria for consulting/advisory role/speaker bureau from Novartis, Eli-Lilly, Pfizer, Roche. E.G.R. has received honoraria for advisory role/speaker bureau from Thermo Fisher Scientific, Roche, Novartis, AstraZeneca. M.I. has received consultation honoraria from Errekappa Euroterapici S.p.a. U.M. reports personal fees (for service in the speaker bureau and as an advisor) from Boehringer Ingelheim, AstraZeneca, Roche, MSD, Amgen, Merck, Eli Lilly, Thermofisher, Diaceutics. N.F. has received honoraria for consulting/advisory role/ speaker bureau from Novartis, Merck Sharp \& Dohme (MSD), and Boehringer Ingelheim. These companies had no role in the design of the study, in the collection, analyses, or interpretation of data, in the writing of the manuscript, and/or in the decision to publish the results. All the other authors declare no conflicts of interest.

\section{REFERENCES}

1. Ribas, A.; Wolchok, J. D., Cancer immunotherapy using checkpoint blockade. Science 2018, 359 (6382), 1350-1355.

2. Pusztai, L.; Karn, T.; Safonov, A.; Abu-Khalaf, M. M.; Bianchini, G., New Strategies in Breast Cancer: Immunotherapy. Clinical cancer research : an official journal of the American Association for Cancer Research 2016, 22 (9), 2105-10.

3. Criscitiello, C.; Curigliano, G., Immunotherapy of Breast Cancer. Progress in tumor research 2015, 42, 30-43.

4. Pagni, F.; Guerini-Rocco, E.; Schultheis, A. M.; Grazia, G.; Rijavec, E.; Ghidini, M.; Lopez, G.; Venetis, K.; Croci, G. A.; Malapelle, U.; Fusco, N., Targeting Immune-Related Biological Processes in Solid Tumors: We do Need Biomarkers. Int J Mol Sci 2019, 20 (21).

5. Barroso-Sousa, R.; Tolaney, S. M., Clinical Development of PD-1/PD-L1 Inhibitors in Breast Cancer: Still a Long Way to Go. Current treatment options in oncology 2020, 21 (7), 59. 
6. Venetis, K.; Invernizzi, M.; Sajjadi, E.; Curigliano, G.; Fusco, N., Cellular immunotherapy in breast cancer: The quest for consistent biomarkers. Cancer Treatment Reviews 2020, 90.

7. Napolitano, M.; Schipilliti, F. M.; Trudu, L.; Bertolini, F., Immunotherapy in head and neck cancer: The great challenge of patient selection. Crit Rev Oncol Hematol 2019, 144, 102829.

8. Signorelli, D.; Giannatempo, P.; Grazia, G.; Aiello, M. M.; Bertolini, F.; Mirabile, A.; Buti, S.; Vasile, E.; Scotti, V.; Pisapia, P.; Cona, M. S.; Rolfo, C.; Malapelle, U., Patients selection for immunotherapy in solid tumors: overcome the naïve vision of a single biomarker. Biomed Res Int 2019, 2019.

9. Lopez, G.; Noale, M.; Corti, C.; Gaudioso, G.; Sajjadi, E.; Venetis, K.; Gambini, D.; Runza, L.; Costanza, J.; Pesenti, C.; Grossi, F.; Maggi, S.; Ferrero, S.; Bosari, S.; Fusco, N., PTEN Expression as a Complementary Biomarker for Mismatch Repair Testing in Breast Cancer. Int J Mol Sci 2020, 21 (4).

10. Fusco, N.; Sajjadi, E.; Venetis, K.; Gaudioso, G.; Lopez, G.; Corti, C.; Rocco, E. G.; Criscitiello, C.; Malapelle, U.; Invernizzi, M., PTEN Alterations and Their Role in Cancer Management: Are We Making Headway on Precision Medicine? Genes 2020, 11 (7), 719.

11. Malone, E. R.; Oliva, M.; Sabatini, P. J. B.; Stockley, T. L.; Siu, L. L., Molecular profiling for precision cancer therapies. Genome Med 2020, 12 (1), 8.

12. Peng, Z.; Su, P.; Yang, Y.; Yao, X.; Zhang, Y.; Jin, F.; Yang, B., Identification of CTLA-4 associated with tumor microenvironment and competing interactions in triple negative breast cancer by co-expression network analysis. Journal of Cancer 2020, 11 (21), 6365-6375.

13. Navarrete-Bernal, M. G. C.; Cervantes-Badillo, M. G.; Martínez-Herrera, J. F.; LaraTorres, C. O.; Gerson-Cwilich, R.; Zentella-Dehesa, A.; Ibarra-Sánchez, M. d. J.; EsparzaLópez, J.; Montesinos, J. J.; Cortés-Morales, V. A.; Osorio-Pérez, D.; Villegas-Osorno, D. A.; Reyes-Sánchez, E.; Salazar-Sojo, P.; Tallabs-Utrilla, L. F.; Romero-Córdoba, S.; RochaZavaleta, L., Biological Landscape of Triple Negative Breast Cancers Expressing CTLA-4. Frontiers in oncology 2020, 10, 1206-1206.

14. Kassardjian, A.; Shintaku, P. I.; Moatamed, N. A., Expression of immune checkpoint regulators, cytotoxic T lymphocyte antigen 4 (CTLA-4) and programmed death-ligand 1 (PD-L1), in female breast carcinomas. PLoS One 2018, 13 (4), e0195958.

15. Larkin, J.; Chiarion-Sileni, V.; Gonzalez, R.; Grob, J. J.; Cowey, C. L.; Lao, C. D.; Schadendorf, D.; Dummer, R.; Smylie, M.; Rutkowski, P.; Ferrucci, P. F.; Hill, A.; Wagstaff, J.; Carlino, M. S.; Haanen, J. B.; Maio, M.; Marquez-Rodas, I.; McArthur, G. A.; Ascierto, P. A.; Long, G. V.; Callahan, M. K.; Postow, M. A.; Grossmann, K.; Sznol, M.; Dreno, B.; Bastholt, L.; Yang, A.; Rollin, L. M.; Horak, C.; Hodi, F. S.; Wolchok, J. D., Combined Nivolumab and Ipilimumab or Monotherapy in Untreated Melanoma. The New England journal of medicine 2015, 373 (1), 23-34.

16. Santabarbara, G.; Maione, P.; Rossi, A.; Palazzolo, G.; Gridelli, C., Novel immunotherapy in the treatment of advanced non-small cell lung cancer. Expert Rev Clin Pharmacol 2016, 9 (12), 1571-1581.

17. Leal, H. S. a. H. M., Breast Cancer Immunotherapy: From Biology to Current Clinical Applications. European Medical Journal, 2020.

18. Nanda, R.; Chow, L. Q.; Dees, E. C.; Berger, R.; Gupta, S.; Geva, R.; Pusztai, L.; Pathiraja, K.; Aktan, G.; Cheng, J. D.; Karantza, V.; Buisseret, L., Pembrolizumab in Patients With Advanced Triple-Negative Breast Cancer: Phase Ib KEYNOTE-012 Study. J Clin Oncol 2016, 34 (21), 2460-7.

19. Adams, S.; Schmid, P.; Rugo, H. S.; Winer, E. P.; Loirat, D.; Awada, A.; Cescon, D. W.; Iwata, H.; Campone, M.; Nanda, R.; Hui, R.; Curigliano, G.; Toppmeyer, D.; O'Shaughnessy, J.; Loi, S.; Paluch-Shimon, S.; Tan, A. R.; Card, D.; Zhao, J.; Karantza, V.; Cortes, J., Pembrolizumab monotherapy for previously treated metastatic triple-negative breast 
cancer: cohort A of the phase II KEYNOTE-086 study. Annals of oncology : official journal of the European Society for Medical Oncology / ESMO 2019, 30 (3), 397-404.

20. Adams, S.; Loi, S.; Toppmeyer, D.; Cescon, D. W.; De Laurentiis, M.; Nanda, R.; Winer, E. P.; Mukai, H.; Tamura, K.; Armstrong, A.; Liu, M. C.; Iwata, H.; Ryvo, L.; Wimberger, P.; Rugo, H. S.; Tan, A. R.; Jia, L.; Ding, Y.; Karantza, V.; Schmid, P., Pembrolizumab monotherapy for previously untreated, PD-L1-positive, metastatic triplenegative breast cancer: cohort B of the phase II KEYNOTE-086 study. Annals of oncology : official journal of the European Society for Medical Oncology / ESMO 2019, 30 (3), 405-411.

21. Emens, L. A.; Cruz, C.; Eder, J. P.; Braiteh, F.; Chung, C.; Tolaney, S. M.; Kuter, I.; Nanda, R.; Cassier, P. A.; Delord, J. P.; Gordon, M. S.; ElGabry, E.; Chang, C. W.; Sarkar, I.; Grossman, W.; O'Hear, C.; Fasso, M.; Molinero, L.; Schmid, P., Long-term Clinical Outcomes and Biomarker Analyses of Atezolizumab Therapy for Patients With Metastatic Triple-Negative Breast Cancer: A Phase 1 Study. JAMA oncology 2019, 5 (1), 74-82.

22. Cyprian, F. S.; Akhtar, S.; Gatalica, Z.; Vranic, S., Targeted immunotherapy with a checkpoint inhibitor in combination with chemotherapy: A new clinical paradigm in the treatment of triple-negative breast cancer. Bosn J Basic Med Sci 2019, 19 (3), 227-233.

23. Marra, A.; Trapani, D.; Viale, G.; Criscitiello, C.; Curigliano, G., Practical classification of triple-negative breast cancer: intratumoral heterogeneity, mechanisms of drug resistance, and novel therapies. NPJ breast cancer 2020, 6, 54.

24. Schmid, P.; Adams, S.; Rugo, H. S.; Schneeweiss, A.; Barrios, C. H.; Iwata, H.; Dieras, V.; Hegg, R.; Im, S. A.; Shaw Wright, G.; Henschel, V.; Molinero, L.; Chui, S. Y.; Funke, R.; Husain, A.; Winer, E. P.; Loi, S.; Emens, L. A.; Investigators, I. M. T., Atezolizumab and Nab-Paclitaxel in Advanced Triple-Negative Breast Cancer. The New England journal of medicine 2018, 379 (22), 2108-2121.

25. Schmid, P.; Rugo, H. S.; Adams, S.; Schneeweiss, A.; Barrios, C. H.; Iwata, H.; Diéras, V.; Henschel, V.; Molinero, L.; Chui, S. Y.; Maiya, V.; Husain, A.; Winer, E. P.; Loi, S.; Emens, L. A., Atezolizumab plus nab-paclitaxel as first-line treatment for unresectable, locally advanced or metastatic triple-negative breast cancer (IMpassion130): updated efficacy results from a randomised, double-blind, placebo-controlled, phase 3 trial. Lancet Oncol 2020, 21 (1), 44-59.

26. Dent, R.; Andre, F.; Goncalves, A.; Kummel, S.; Martin, M.; Schmid, P.; Schuetz, F.; Swain, S. M.; Easton, V.; Pollex, E.; Cortés, J., IMpassion132: A double-blind randomized phase 3 trial evaluating chemotherapy (CT) \pm atezolizumab (atezo) for early progressing locally advanced/metastatic triple-negative breast cancer (mTNBC). Journal of Clinical Oncology 2018, 36 (15_suppl), TPS1115-TPS1115.

27. Cortés, J.; André, F.; Gonçalves, A.; Kümmel, S.; Martín, M.; Schmid, P.; Schuetz, F.; Swain, S. M.; Easton, V.; Pollex, E.; Deurloo, R.; Dent, R., IMpassion132 Phase III trial: atezolizumab and chemotherapy in early relapsing metastatic triple-negative breast cancer. Future Oncol 2019, 15 (17), 1951-1961.

28. Cortes, J.; Cescon, D. W.; Rugo, H. S.; Nowecki, Z.; Im, S. A.; Yusof, M. M.; Gallardo, C.; Lipatov, O.; Barrios, C. H.; Holgado, E.; Iwata, H.; Masuda, N.; Otero, M. T.; Gokmen, E.; Loi, S.; Guo, Z.; Zhao, J.; Aktan, G.; Karantza, V.; Schmid, P., Pembrolizumab plus chemotherapy versus placebo plus chemotherapy for previously untreated locally recurrent inoperable or metastatic triple-negative breast cancer (KEYNOTE-355): a randomised, placebocontrolled, double-blind, phase 3 clinical trial. Lancet 2020, 396 (10265), 1817-1828.

29. Kulangara, K.; Zhang, N.; Corigliano, E.; Guerrero, L.; Waldroup, S.; Jaiswal, D.; Ms, M. J.; Shah, S.; Hanks, D.; Wang, J.; Lunceford, J.; Savage, M. J.; Juco, J.; Emancipator, K., Clinical Utility of the Combined Positive Score for Programmed Death Ligand-1 Expression and the Approval of Pembrolizumab for Treatment of Gastric Cancer. Archives of pathology \& laboratory medicine 2019, 143 (3), 330-337. 
30. Ogiya, R.; Niikura, N.; Kumaki, N.; Bianchini, G.; Kitano, S.; Iwamoto, T.; Hayashi, N.; Yokoyama, K.; Oshitanai, R.; Terao, M.; Morioka, T.; Tsuda, B.; Okamura, T.; Saito, Y.; Suzuki, Y.; Tokuda, Y., Comparison of tumor-infiltrating lymphocytes between primary and metastatic tumors in breast cancer patients. Cancer science 2016, 107 (12), 1730-1735.

31. Luen, S. J.; Salgado, R.; Fox, S.; Savas, P.; Eng-Wong, J.; Clark, E.; Kiermaier, A.; Swain, S. M.; Baselga, J.; Michiels, S.; Loi, S., Tumour-infiltrating lymphocytes in advanced HER2-positive breast cancer treated with pertuzumab or placebo in addition to trastuzumab and docetaxel: a retrospective analysis of the CLEOPATRA study. The lancet oncology 2017, 18 (1), 52-62.

32. Dieci, M. V.; Tsvetkova, V.; Orvieto, E.; Piacentini, F.; Ficarra, G.; Griguolo, G.; Miglietta, F.; Giarratano, T.; Omarini, C.; Bonaguro, S.; Cappellesso, R.; Aliberti, C.; Vernaci, G.; Giorgi, C. A.; Faggioni, G.; Tasca, G.; Conte, P.; Guarneri, V., Immune characterization of breast cancer metastases: prognostic implications. Breast cancer research : BCR 2018, 20 (1), 62.

33. Szekely, B.; Bossuyt, V.; Li, X.; Wali, V. B.; Patwardhan, G. A.; Frederick, C.; Silber, A.; Park, T.; Harigopal, M.; Pelekanou, V.; Zhang, M.; Yan, Q.; Rimm, D. L.; Bianchini, G.; Hatzis, C.; Pusztai, L., Immunological differences between primary and metastatic breast cancer. Ann Oncol 2018, 29 (11), 2232-2239.

34. Schmid, P.; Cortes, J.; Pusztai, L.; McArthur, H.; Kümmel, S.; Bergh, J.; Denkert, C.; Park, Y. H.; Hui, R.; Harbeck, N.; Takahashi, M.; Foukakis, T.; Fasching, P. A.; Cardoso, F.; Untch, M.; Jia, L.; Karantza, V.; Zhao, J.; Aktan, G.; Dent, R.; O'Shaughnessy, J., Pembrolizumab for Early Triple-Negative Breast Cancer. N Engl J Med 2020, 382 (9), 810-821.

35. Loibl, S.; Untch, M.; Burchardi, N.; Huober, J.; Sinn, B. V.; Blohmer, J. U.; Grischke, E. M.; Furlanetto, J.; Tesch, H.; Hanusch, C.; Engels, K.; Rezai, M.; Jackisch, C.; Schmitt, W. D.; von Minckwitz, G.; Thomalla, J.; Kümmel, S.; Rautenberg, B.; Fasching, P. A.; Weber, K.; Rhiem, K.; Denkert, C.; Schneeweiss, A., A randomised phase II study investigating durvalumab in addition to an anthracycline taxane-based neoadjuvant therapy in early triple-negative breast cancer: clinical results and biomarker analysis of GeparNuevo study. Ann Oncol 2019, 30 (8), 1279-1288.

36. Gianni, L.; Huang, C.-S.; Egle, D.; Bermejo, B.; Zamagni, C.; Thill, M.; Anton, A.; Zambelli, S.; Bianchini, G.; Russo, S.; Ciruelos, E.; Greil, R.; Semiglazov, V.; Colleoni, M.; Kelly, C.; Mariani, G.; Mastro, L. D.; Maffeis, I.; Valagussa, P.; Viale, G., Abstract GS3-04: Pathologic complete response ( $\mathrm{pCR}$ ) to neoadjuvant treatment with or without atezolizumab in triple negative, early high-risk and locally advanced breast cancer. NeoTRIPaPDL1 Michelangelo randomized study. Cancer Research 2020, 80 (4 Supplement), GS3-04.

37. Dirix, L. Y.; Takacs, I.; Jerusalem, G.; Nikolinakos, P.; Arkenau, H. T.; Forero-Torres, A.; Boccia, R.; Lippman, M. E.; Somer, R.; Smakal, M.; Emens, L. A.; Hrinczenko, B.; Edenfield, W.; Gurtler, J.; von Heydebreck, A.; Grote, H. J.; Chin, K.; Hamilton, E. P., Avelumab, an anti-PD-L1 antibody, in patients with locally advanced or metastatic breast cancer: a phase 1b JAVELIN Solid Tumor study. Breast cancer research and treatment 2018, $167(3), 671-686$.

38. Rugo, H. S.; Delord, J. P.; Im, S. A.; Ott, P. A.; Piha-Paul, S. A.; Bedard, P. L.; Sachdev, J.; Le Tourneau, C.; van Brummelen, E. M. J.; Varga, A.; Salgado, R.; Loi, S.; Saraf, S.; Pietrangelo, D.; Karantza, V.; Tan, A. R., Safety and Antitumor Activity of Pembrolizumab in Patients with Estrogen Receptor-Positive/Human Epidermal Growth Factor Receptor 2-Negative Advanced Breast Cancer. Clinical cancer research : an official journal of the American Association for Cancer Research 2018, 24 (12), 2804-2811.

39. Tolaney, S. M.; Barroso-Sousa, R.; Keenan, T.; Trippa, L.; Hu, J.; Luis, I. M. V. D.; Wulf, G. M.; Spring, L.; Sinclair, N. F.; Andrews, C.; Pittenger, J. D.; Richardson, E. T.; Dillon, D.; Lin, N. U.; Overmoyer, B.; Partridge, A. H.; VanAllen, E.; Mittendorf, E. A.; Winer, E. P.; Krop, I. E., Randomized phase II study of eribulin mesylate (E) with or without 
pembrolizumab (P) for hormone receptor-positive (HR plus ) metastatic breast cancer (MBC). Journal of Clinical Oncology 2019, 37 (15).

40. Goel, S.; DeCristo, M. J.; Watt, A. C.; BrinJones, H.; Sceneay, J.; Li, B. B.; Khan, N.; Ubellacker, J. M.; Xie, S.; Metzger-Filho, O.; Hoog, J.; Ellis, M. J.; Ma, C. X.; Ramm, S.; Krop, I. E.; Winer, E. P.; Roberts, T. M.; Kim, H.-J.; McAllister, S. S.; Zhao, J. J., CDK4/6 inhibition triggers anti-tumour immunity. Nature 2017, 548 (7668), 471-475.

41. Rugo, H. S.; Kabos, P.; Beck, J. T.; Chisamore, M. J.; Hossain, A.; Chen, Y.; Tolaney, S. M., A phase lb study of abemaciclib in combination with pembrolizumab for patients with hormone receptor positive $(\mathrm{HR}+)$, human epidermal growth factor receptor 2 negative (HER2-) locally advanced or metastatic breast cancer (MBC) (NCT02779751): Interim results. Journal of Clinical Oncology 2020, 38 (15 suppl), 1051-1051.

42. Loi, S.; Giobbie-Hurder, A.; Gombos, A.; Bachelot, T.; Hui, R.; Curigliano, G.; Campone, M.; Biganzoli, L.; Bonnefoi, H.; Jerusalem, G.; Bartsch, R.; Rabaglio-Poretti, M.; Kammler, R.; Maibach, R.; Smyth, M. J.; Di Leo, A.; Colleoni, M.; Viale, G.; Regan, M. M.; Andre, F.; International Breast Cancer Study, G.; the Breast International, G., Pembrolizumab plus trastuzumab in trastuzumab-resistant, advanced, HER2-positive breast cancer (PANACEA): a single-arm, multicentre, phase 1b-2 trial. The lancet oncology 2019, 20 (3), 371382.

43. Emens, L. A.; Esteva, F. J.; Beresford, M.; Saura, C.; De Laurentiis, M.; Kim, S. B.; Im, S. A.; Wang, Y.; Salgado, R.; Mani, A.; Shah, J.; Lambertini, C.; Liu, H.; de Haas, S. L.; Patre, M.; Loi, S., Trastuzumab emtansine plus atezolizumab versus trastuzumab emtansine plus placebo in previously treated, HER2-positive advanced breast cancer (KATE2): a phase 2, multicentre, randomised, double-blind trial. The lancet oncology 2020, 21 (10), 1283-1295.

44. Bedard, P. L.; Hyman, D. M.; Davids, M. S.; Siu, L. L., Small molecules, big impact: 20 years of targeted therapy in oncology. The Lancet 2020, 395 (10229), 1078-1088.

45. Guo, L.; Wei, R.; Lin, Y.; Kwok, H. F., Clinical and Recent Patents Applications of PD1/PD-L1 Targeting Immunotherapy in Cancer Treatment-Current Progress, Strategy, and Future Perspective. Front Immunol 2020, 11, 1508.

46. Shaabani, S.; Huizinga, H. P. S.; Butera, R.; Kouchi, A.; Guzik, K.; Magiera-Mularz, K.; Holak, T. A.; Dömling, A., A patent review on PD-1/PD-L1 antagonists: small molecules, peptides, and macrocycles (2015-2018). Expert Opin Ther Pat 2018, 28 (9), 665-678.

47. Guzik, K.; Tomala, M.; Muszak, D.; Konieczny, M.; Hec, A.; Błaszkiewicz, U.; Pustuła, M.; Butera, R.; Dömling, A.; Holak, T. A., Development of the Inhibitors that Target the PD-1/PD-L1 Interaction-A Brief Look at Progress on Small Molecules, Peptides and Macrocycles. Molecules 2019, 24 (11).

48. $\quad$ Smith, W. M.; Purvis, I. J.; Bomstad, C. N.; Labak, C. M.; Velpula, K. K.; Tsung, A. J.; Regan, J. N.; Venkataraman, S.; Vibhakar, R.; Asuthkar, S., Therapeutic targeting of immune checkpoints with small molecule inhibitors. Am J Transl Res 2019, 11 (2), 529-541.

49. Skalniak, L.; Zak, K. M.; Guzik, K.; Magiera, K.; Musielak, B.; Pachota, M.; Szelazek, B.; Kocik, J.; Grudnik, P.; Tomala, M.; Krzanik, S.; Pyrc, K.; Dömling, A.; Dubin, G.; Holak, T. A., Small-molecule inhibitors of PD-1/PD-L1 immune checkpoint alleviate the PD-L1-induced exhaustion of T-cells. Oncotarget 2017, 8 (42), 72167-72181.

50. Ganesan, A.; Ahmed, M.; Okoye, I.; Arutyunova, E.; Babu, D.; Turnbull, W. L.; Kundu, J. K.; Shields, J.; Agopsowicz, K. C.; Xu, L.; Tabana, Y.; Srivastava, N.; Zhang, G.; Moon, T. C.; Belovodskiy, A.; Hena, M.; Kandadai, A. S.; Hosseini, S. N.; Hitt, M.; Walker, J.; Smylie, M.; West, F. G.; Siraki, A. G.; Lemieux, M. J.; Elahi, S.; Nieman, J. A.; Tyrrell, D. L.; Houghton, M.; Barakat, K., Comprehensive in vitro characterization of PD-L1 small molecule inhibitors. Scientific Reports 2019, 9 (1), 12392.

51. Konieczny, M.; Musielak, B.; Kocik, J.; Skalniak, L.; Sala, D.; Czub, M.; MagieraMularz, K.; Rodriguez, I.; Myrcha, M.; Stec, M.; Siedlar, M.; Holak, T. A.; Plewka, J., Di- 
bromo-Based Small-Molecule Inhibitors of the PD-1/PD-L1 Immune Checkpoint. J Med Chem 2020, 63 (19), 11271-11285.

52. Li, K.; Tian, H., Development of small-molecule immune checkpoint inhibitors of PD1/PD-L1 as a new therapeutic strategy for tumour immunotherapy. Journal of Drug Targeting 2019, 27 (3), 244-256.

53. Musielak, B.; Kocik, J.; Skalniak, L.; Magiera-Mularz, K.; Sala, D.; Czub, M.; Stec, M.; Siedlar, M.; Holak, T. A.; Plewka, J., CA-170 - A Potent Small-Molecule PD-L1 Inhibitor or Not? Molecules 2019, 24 (15).

54. Tomioka, N.; Azuma, M.; Ikarashi, M.; Yamamoto, M.; Sato, M.; Watanabe, K. I.; Yamashiro, K.; Takahashi, M., The therapeutic candidate for immune checkpoint inhibitors elucidated by the status of tumor-infiltrating lymphocytes (TILs) and programmed death ligand 1 (PD-L1) expression in triple negative breast cancer (TNBC). Breast Cancer 2018, 25 (1), 34-42.

55. Mills, A. M.; Dill, E. A.; Moskaluk, C. A.; Dziegielewski, J.; Bullock, T. N.; Dillon, P. M., The Relationship Between Mismatch Repair Deficiency and PD-L1 Expression in Breast Carcinoma. Am J Surg Pathol 2018, 42 (2), 183-191.

56. Curigliano, G.; Burstein, H. J.; P Winer, E.; Gnant, M.; Dubsky, P.; Loibl, S.; Colleoni, M.; Regan, M. M.; Piccart-Gebhart, M.; Senn, H. J.; Thürlimann, B.; André, F.; Baselga, J.; Bergh, J.; Bonnefoi, H.; Y Brucker, S.; Cardoso, F.; Carey, L.; Ciruelos, E.; Cuzick, J.; Denkert, C.; Di Leo, A.; Ejlertsen, B.; Francis, P.; Galimberti, V.; Garber, J.; Gulluoglu, B.; Goodwin, P.; Harbeck, N.; Hayes, D. F.; Huang, C. S.; Huober, J.; Hussein, K.; Jassem, J.; Jiang, Z.; Karlsson, P.; Morrow, M.; Orecchia, R.; Osborne, K. C.; Pagani, O.; Partridge, A. H.; Pritchard, K.; Ro, J.; Rutgers, E. J. T.; Sedlmayer, F.; Semiglazov, V.; Shao, Z.; Smith, I.; Toi, M.; Tutt, A.; Viale, G.; Watanabe, T.; Whelan, T. J.; Xu, B.; 2017, S. G. I. E. C. o. t. P. T. o. E. B. C., De-escalating and escalating treatments for early-stage breast cancer: the St. Gallen International Expert Consensus Conference on the Primary Therapy of Early Breast Cancer 2017. Ann Oncol 2017, 28 (8), 1700-1712.

57. Reis-Filho, J. S.; Tutt, A. N., Triple negative tumours: a critical review. Histopathology 2008, $52(1), 108-18$.

58. Mao, Y.; Qu, Q.; Chen, X.; Huang, O.; Wu, J.; Shen, K., The Prognostic Value of Tumor-Infiltrating Lymphocytes in Breast Cancer: A Systematic Review and Meta-Analysis. PLoS One 2016, 11 (4), e0152500.

59. Rooney, M. S.; Shukla, S. A.; Wu, C. J.; Getz, G.; Hacohen, N., Molecular and genetic properties of tumors associated with local immune cytolytic activity. Cell 2015, 160 (1-2), 48-61.

60. Zitvogel, L.; Apetoh, L.; Ghiringhelli, F.; Kroemer, G., Immunological aspects of cancer chemotherapy. Nat Rev Immunol 2008, 8 (1), 59-73.

61. Wang, Y.; Waters, J.; Leung, M. L.; Unruh, A.; Roh, W.; Shi, X.; Chen, K.; Scheet, P.; Vattathil, S.; Liang, H.; Multani, A.; Zhang, H.; Zhao, R.; Michor, F.; Meric-Bernstam, F.; Navin, N. E., Clonal evolution in breast cancer revealed by single nucleus genome sequencing. Nature 2014, 512 (7513), 155-60.

62. Fusco, N.; Vaira, V.; Righi, I.; Sajjadi, E.; Venetis, K.; Lopez, G.; Cattaneo, M.; Castellani, M.; Rosso, L.; Nosotti, M.; Clerici, M.; Ferrero, S., Characterization of the immune microenvironment in malignant pleural mesothelioma reveals prognostic subgroups of patients. Lung Cancer 2020, 150, 53-61.

63. Denkert, C.; Loibl, S.; Noske, A.; Roller, M.; Müller, B. M.; Komor, M.; Budczies, J.; Darb-Esfahani, S.; Kronenwett, R.; Hanusch, C.; von Törne, C.; Weichert, W.; Engels, K.; Solbach, C.; Schrader, I.; Dietel, M.; von Minckwitz, G., Tumor-associated lymphocytes as an independent predictor of response to neoadjuvant chemotherapy in breast cancer. $J$ Clin Oncol 2010, 28 (1), 105-13.

64. Salgado, R.; Denkert, C.; Demaria, S.; Sirtaine, N.; Klauschen, F.; Pruneri, G.; Wienert, S.; Van den Eynden, G.; Baehner, F. L.; Penault-Llorca, F.; Perez, E. A.; Thompson, E. A.; Symmans, W. F.; Richardson, A. L.; Brock, J.; Criscitiello, C.; Bailey, H.; 
Ignatiadis, M.; Floris, G.; Sparano, J.; Kos, Z.; Nielsen, T.; Rimm, D. L.; Allison, K. H.; ReisFilho, J. S.; Loibl, S.; Sotiriou, C.; Viale, G.; Badve, S.; Adams, S.; Willard-Gallo, K.; Loi, S., The evaluation of tumor-infiltrating lymphocytes (TILs) in breast cancer: recommendations by an International TILs Working Group 2014. Ann Oncol 2015, 26 (2), 259-71.

65. Denkert, C.; Wienert, S.; Poterie, A.; Loibl, S.; Budczies, J.; Badve, S.; BagoHorvath, Z.; Bane, A.; Bedri, S.; Brock, J.; Chmielik, E.; Christgen, M.; Colpaert, C.; Demaria, S.; Van den Eynden, G.; Floris, G.; Fox, S. B.; Gao, D.; Ingold Heppner, B.; Kim, S. R.; Kos, Z.; Kreipe, H. H.; Lakhani, S. R.; Penault-Llorca, F.; Pruneri, G.; RadosevicRobin, N.; Rimm, D. L.; Schnitt, S. J.; Sinn, B. V.; Sinn, P.; Sirtaine, N.; O'Toole, S. A.; Viale, G.; Van de Vijver, K.; de Wind, R.; von Minckwitz, G.; Klauschen, F.; Untch, M.; Fasching, P. A.; Reimer, T.; Willard-Gallo, K.; Michiels, S.; Loi, S.; Salgado, R., Standardized evaluation of tumor-infiltrating lymphocytes in breast cancer: results of the ring studies of the international immuno-oncology biomarker working group. Mod Pathol 2016, 29 (10), 1155-64.

66. Loi, S.; Michiels, S.; Salgado, R.; Sirtaine, N.; Jose, V.; Fumagalli, D.; KellokumpuLehtinen, P. L.; Bono, P.; Kataja, V.; Desmedt, C.; Piccart, M. J.; Loibl, S.; Denkert, C.; Smyth, M. J.; Joensuu, H.; Sotiriou, C., Tumor infiltrating lymphocytes are prognostic in triple negative breast cancer and predictive for trastuzumab benefit in early breast cancer: results from the FinHER trial. Ann Oncol 2014, 25 (8), 1544-50.

67. Ali, H. R.; Provenzano, E.; Dawson, S. J.; Blows, F. M.; Liu, B.; Shah, M.; Earl, H. M.; Poole, C. J.; Hiller, L.; Dunn, J. A.; Bowden, S. J.; Twelves, C.; Bartlett, J. M.; Mahmoud, S. M.; Rakha, E.; Ellis, I. O.; Liu, S.; Gao, D.; Nielsen, T. O.; Pharoah, P. D.; Caldas, C., Association between CD8+ T-cell infiltration and breast cancer survival in 12,439 patients. Ann Oncol 2014, 25 (8), 1536-43.

68. Salgado, R.; Denkert, C.; Campbell, C.; Savas, P.; Nuciforo, P.; Aura, C.; de Azambuja, E.; Eidtmann, H.; Ellis, C. E.; Baselga, J.; Piccart-Gebhart, M. J.; Michiels, S.; Bradbury, I.; Sotiriou, C.; Loi, S., Tumor-Infiltrating Lymphocytes and Associations With Pathological Complete Response and Event-Free Survival in HER2-Positive Early-Stage Breast Cancer Treated With Lapatinib and Trastuzumab: A Secondary Analysis of the NeoALTTO Trial. JAMA Oncol 2015, 1 (4), 448-54.

69. Adams, S.; Gray, R. J.; Demaria, S.; Goldstein, L.; Perez, E. A.; Shulman, L. N.; Martino, S.; Wang, M.; Jones, V. E.; Saphner, T. J.; Wolff, A. C.; Wood, W. C.; Davidson, N. E.; Sledge, G. W.; Sparano, J. A.; Badve, S. S., Prognostic value of tumor-infiltrating lymphocytes in triple-negative breast cancers from two phase III randomized adjuvant breast cancer trials: ECOG 2197 and ECOG 1199. J Clin Oncol 2014, 32 (27), 2959-66.

70. Park, J. H.; Jonas, S. F.; Bataillon, G.; Criscitiello, C.; Salgado, R.; Loi, S.; Viale, G.; Lee, H. J.; Dieci, M. V.; Kim, S. B.; Vincent-Salomon, A.; Curigliano, G.; André, F.; Michiels, S., Prognostic value of tumor-infiltrating lymphocytes in patients with early-stage triple-negative breast cancers (TNBC) who did not receive adjuvant chemotherapy. Ann Oncol 2019, 30 (12), $1941-1949$.

71. Dieci, M. V.; Criscitiello, C.; Goubar, A.; Viale, G.; Conte, P.; Guarneri, V.; Ficarra, G.; Mathieu, M. C.; Delaloge, S.; Curigliano, G.; Andre, F., Prognostic value of tumorinfiltrating lymphocytes on residual disease after primary chemotherapy for triple-negative breast cancer: a retrospective multicenter study. Ann Oncol 2014, 25 (3), 611-618.

72. Loi, S.; Adams, S.; Schmid, P.; Cortés, J.; Cescon, D. W.; Winer, E. P.; Toppmeyer, D. L.; Rugo, H. S.; De Laurentiis, M.; Nanda, R.; Iwata, H.; Awada, A.; Tan, A.; Wang, A.; Aktan, G.; Karantza, V.; Salgado, R., Relationship between tumor infiltrating lymphocyte (TIL) levels and response to pembrolizumab (pembro) in metastatic triple-negative breast cancer (mTNBC): Results from KEYNOTE-086. Annals of Oncology 2017, 28, v608.

73. Adams, S.; Schmid, P.; Rugo, H. S.; Winer, E. P.; Loirat, D.; Awada, A.; Cescon, D. W.; Iwata, H.; Campone, M.; Nanda, R.; Hui, R.; Curigliano, G.; Toppmeyer, D.; O'Shaughnessy, J.; Loi, S.; Paluch-Shimon, S.; Tan, A. R.; Card, D.; Zhao, J.; Karantza, V.; 
Cortés, J., Pembrolizumab monotherapy for previously treated metastatic triple-negative breast cancer: cohort A of the phase II KEYNOTE-086 study. Ann Oncol 2019, 30 (3), 397-404.

74. Loi, S.; Giobbie-Hurder, A.; Gombos, A.; Bachelot, T.; Hui, R.; Curigliano, G.; Campone, M.; Biganzoli, L.; Bonnefoi, H.; Jerusalem, G.; Bartsch, R.; Rabaglio-Poretti, M.; Kammler, R.; Maibach, R.; Smyth, M. J.; Di Leo, A.; Colleoni, M.; Viale, G.; Regan, M. M.; André, F., Pembrolizumab plus trastuzumab in trastuzumab-resistant, advanced, HER2-positive breast cancer (PANACEA): a single-arm, multicentre, phase 1b-2 trial. Lancet Oncol 2019, 20 (3), 371-382.

75. Zou, Y.; Zou, X.; Zheng, S.; Tang, H.; Zhang, L.; Liu, P.; Xie, X., Efficacy and predictive factors of immune checkpoint inhibitors in metastatic breast cancer: a systematic review and meta-analysis. Ther Adv Med Oncol 2020, 12, 1758835920940928.

76. Pusztai, L.; Hofstatter, E. W.; Chung, G. G.; Horowitz, N. R.; Lannin, D. R.; Killelea, B. K.; Chagpar, A. B.; DiGiovanna, M.; Frederick, C.; Burello, T.; Harigopal, M., Durvalumab (MEDI4736) concurrent with nab-paclitaxel and dose dense doxorubicin cyclophosphamide (ddAC) as neoadjuvant therapy for triple negative breast cancer (TNBC). J Clin Oncol 2018.

77. Schnell, A.; Bod, L.; Madi, A.; Kuchroo, V. K., The yin and yang of co-inhibitory receptors: toward anti-tumor immunity without autoimmunity. Cell Research 2020, 30 (4), 285299.

78. Dermani, F. K.; Samadi, P.; Rahmani, G.; Kohlan, A. K.; Najafi, R., PD-1/PD-L1 immune checkpoint: Potential target for cancer therapy. J Cell Physiol 2019, 234 (2), 13131325.

79. Cha, J. H.; Chan, L. C.; Li, C. W.; Hsu, J. L.; Hung, M. C., Mechanisms Controlling PDL1 Expression in Cancer. Mol Cell 2019, 76 (3), 359-370.

80. Bastaki, S.; Irandoust, M.; Ahmadi, A.; Hojjat-Farsangi, M.; Ambrose, P.; Hallaj, S.; Edalati, M.; Ghalamfarsa, G.; Azizi, G.; Yousefi, M.; Chalajour, H.; Jadidi-Niaragh, F., PDL1/PD-1 axis as a potent therapeutic target in breast cancer. Life Sci 2020, 247, 117437.

81. Baptista, M. Z.; Sarian, L. O.; Derchain, S. F.; Pinto, G. A.; Vassallo, J., Prognostic significance of PD-L1 and PD-L2 in breast cancer. Hum Pathol 2016, 47 (1), 78-84.

82. Han, Y.; Liu, D.; Li, L., PD-1/PD-L1 pathway: current researches in cancer. Am J Cancer Res 2020, 10 (3), 727-742.

83. Zhang, J. Y.; Yan, Y. Y.; Li, J. J.; Adhikari, R.; Fu, L. W., PD-1/PD-L1 Based Combinational Cancer Therapy: Icing on the Cake. Front Pharmacol 2020, 11, 722.

84. Seliger, B., Basis of PD1/PD-L1 Therapies. J Clin Med 2019, 8 (12).

85. Tokumaru, Y.; Joyce, D.; Takabe, K., Current status and limitations of immunotherapy for breast cancer. Surgery 2020, 167 (3), 628-630.

86. de Melo Gagliato, D.; Buzaid, A. C.; Perez-Garcia, J.; Cortes, J., Immunotherapy in Breast Cancer: Current Practice and Clinical Challenges. BioDrugs 2020, 34 (5), 611-623.

87. Rugo, H. S.; Loi, S.; Adams, S.; Schmid, P.; Schneeweiss, A.; Barrios, C. H.; Iwata, H.; Dieras, V. C.; Winer, E. P.; Kockx, M.; Peeters, D.; Chui, S. Y.; Lin, J. C.; Nguyen Duc, A.; Viale, G.; Molinero, L.; Emens, L. A., LBA20 - Performance of PD-L1 immunohistochemistry (IHC) assays in unresectable locally advanced or metastatic triplenegative breast cancer (mTNBC): Post-hoc analysis of IMpassion130. Annals of Oncology 2019, 30, v858-v859.

88. Corti, C.; Sajjadi, E.; Fusco, N., Determination of Mismatch Repair Status in Human Cancer and Its Clinical Significance: Does One Size Fit All? Adv Anat Pathol 2019, 26 (4), 270279.

89. Gupta, D.; Heinen, C. D., The mismatch repair-dependent DNA damage response: Mechanisms and implications. DNA Repair (Amst) 2019, 78, 60-69.

90. Bradford, K. C.; Wilkins, H.; Hao, P.; Li, Z. M.; Wang, B.; Burke, D.; Wu, D.; Smith, A. E.; Spaller, L.; Du, C.; Gauer, J. W.; Chan, E.; Hsieh, P.; Weninger, K. R.; Erie, D. A., 
Dynamic human MutSa-MutLa complexes compact mismatched DNA. Proc Natl Acad Sci U S A 2020, $117(28), 16302-16312$.

91. Li, K.; Luo, H.; Huang, L.; Zhu, X., Microsatellite instability: a review of what the oncologist should know. Cancer Cell Int 2020, 20, 16.

92. Zhang, J.; Shih, D. J. H.; Lin, S.-Y., Role of DNA repair defects in predicting immunotherapy response. Biomarker Research 2020, 8 (1), 23.

93. Venetis, K.; Sajjadi, E.; Haricharan, S.; Fusco, N., Mismatch repair testing in breast cancer: the path to tumor-specific immuno-oncology biomarkers. Translational Cancer Research 2020.

94. Boyiadzis, M. M.; Kirkwood, J. M.; Marshall, J. L.; Pritchard, C. C.; Azad, N. S.; Gulley, J. L., Significance and implications of FDA approval of pembrolizumab for biomarkerdefined disease. J Immunother Cancer 2018, 6 (1), 35.

95. Musacchio, L.; Boccia, S. M.; Caruso, G.; Santangelo, G.; Fischetti, M.; Tomao, F.; Perniola, G.; Palaia, I.; Muzii, L.; Pignata, S.; Benedetti Panici, P.; Di Donato, V., Immune Checkpoint Inhibitors: A Promising Choice for Endometrial Cancer Patients? J Clin Med 2020, 9 (6).

96. U.S. Food and Drug Administration FDA approves pembrolizumab for first-line treatment of MSI-H/dMMR colorectal cancer | FDA https://www.fda.gov/drugs/drug-approvals-anddatabases/fda-approves-pembrolizumab-first-line-treatment-msi-hdmmr-colorectal-

cancer\#: :text=On\%20June\%2029\%2C\%202020\%2C\%20the,deficient\%20(dMMR)\%20colorec tal\%20cancer. (accessed 23/9/2020).

97. Cheng, A. S.; Leung, S. C. Y.; Gao, D.; Burugu, S.; Anurag, M.; Ellis, M. J.; Nielsen, T. O., Mismatch repair protein loss in breast cancer: clinicopathological associations in a large British Columbia cohort. In Breast Cancer Res Treat, 2020; Vol. 179, pp 3-10.

98. Fusco, N.; Lopez, G.; Corti, C.; Pesenti, C.; Colapietro, P.; Ercoli, G.; Gaudioso, G.; Faversani, A.; Gambini, D.; Michelotti, A.; Despini, L.; Blundo, C.; Vaira, V.; Miozzo, M.; Ferrero, S.; Bosari, S., Mismatch Repair Protein Loss as a Prognostic and Predictive Biomarker in Breast Cancers Regardless of Microsatellite Instability. JNCI Cancer Spectr 2018, 2 (4), pky056.

99. Lee, S. E.; Lee, H. S.; Kim, K. Y.; Park, J. H.; Roh, H.; Park, H. Y.; Kim, W. S., High prevalence of the MLH1 V384D germline mutation in patients with HER2-positive luminal B breast cancer. Sci Rep 2019, 9 (1), 10966.

100. Le, D. T.; Durham, J. N.; Smith, K. N.; Wang, H.; Bartlett, B. R.; Aulakh, L. K.; Lu, S.; Kemberling, H.; Wilt, C.; Luber, B. S.; Wong, F.; Azad, N. S.; Rucki, A. A.; Laheru, D.; Donehower, R.; Zaheer, A.; Fisher, G. A.; Crocenzi, T. S.; Lee, J. J.; Greten, T. F.; Duffy, A. G.; Ciombor, K. K.; Eyring, A. D.; Lam, B. H.; Joe, A.; Kang, S. P.; Holdhoff, M.; Danilova, L.; Cope, L.; Meyer, C.; Zhou, S.; Goldberg, R. M.; Armstrong, D. K.; Bever, K. M.; Fader, A. N.; Taube, J.; Housseau, F.; Spetzler, D.; Xiao, N.; Pardoll, D. M.; Papadopoulos, N.; Kinzler, K. W.; Eshleman, J. R.; Vogelstein, B.; Anders, R. A.; Diaz, L. A., Mismatch-repair deficiency predicts response of solid tumors to PD-1 blockade. Science 2017, 357 (6349), 40913.

101. Davies, H.; Morganella, S.; Purdie, C. A.; Jang, S. J.; Borgen, E.; Russnes, H.; Glodzik, D.; Zou, X.; Viari, A.; Richardson, A. L.; Børresen-Dale, A. L.; Thompson, A.; Eyfjord, J. E.; Kong, G.; Stratton, M. R.; Nik-Zainal, S., Whole-Genome Sequencing Reveals Breast Cancers with Mismatch Repair Deficiency. Cancer Res 2017, 77 (18), 4755-4762.

102. Fremd, C.; Hlevnjak, M.; Zapatka, M.; Zoernig, I.; Halama, N.; Fejzibegovic, N.; Thewes, V.; Lichter, P.; Schirmacher, P.; Kloor, M.; Marmé, F.; Schütz, F.; Kosaloglu, Z.; Sinn, H. P.; Jäger, D.; Schneeweiss, A., Mismatch Repair Deficiency Drives Durable Complete Remission by Targeting Programmed Death Receptor 1 in a Metastatic Luminal Breast Cancer Patient. In Breast Care (Basel), 2019; Vol. 14, pp 53-59. 
103. Zehir, A.; Benayed, R.; Shah, R. H.; Syed, A.; Middha, S.; Kim, H. R.; Srinivasan, P.; Gao, J.; Chakravarty, D.; Devlin, S. M.; Hellmann, M. D.; Barron, D. A.; Schram, A. M.; Hameed, M.; Dogan, S.; Ross, D. S.; Hechtman, J. F.; DeLair, D. F.; Yao, J.; Mandelker, D. L.; Cheng, D. T.; Chandramohan, R.; Mohanty, A. S.; Ptashkin, R. N.; Jayakumaran, G.; Prasad, M.; Syed, M. H.; Rema, A. B.; Liu, Z. Y.; Nafa, K.; Borsu, L.; Sadowska, J.; Casanova, J.; Bacares, R.; Kiecka, I. J.; Razumova, A.; Son, J. B.; Stewart, L.; Baldi, T.; Mullaney, K. A.; Al-Ahmadie, H.; Vakiani, E.; Abeshouse, A. A.; Penson, A. V.; Jonsson, P.; Camacho, N.; Chang, M. T.; Won, H. H.; Gross, B. E.; Kundra, R.; Heins, Z. J.; Chen, H. W.; Phillips, S.; Zhang, H.; Wang, J.; Ochoa, A.; Wills, J.; Eubank, M.; Thomas, S. B.; Gardos, S. M.; Reales, D. N.; Galle, J.; Durany, R.; Cambria, R.; Abida, W.; Cercek, A.; Feldman, D. R.; Gounder, M. M.; Hakimi, A. A.; Harding, J. J.; lyer, G.; Janjigian, Y. Y.; Jordan, E. J.; Kelly, C. M.; Lowery, M. A.; Morris, L. G. T.; Omuro, A. M.; Raj, N.; Razavi, P.; Shoushtari, A. N.; Shukla, N.; Soumerai, T. E.; Varghese, A. M.; Yaeger, R.; Coleman, J.; Bochner, B.; Riely, G. J.; Saltz, L. B.; Scher, H. I.; Sabbatini, P. J.; Robson, M. E.; Klimstra, D. S.; Taylor, B. S.; Baselga, J.; Schultz, N.; Hyman, D. M.; Arcila, M. E.; Solit, D. B.; Ladanyi, M.; Berger, M. F., Mutational landscape of metastatic cancer revealed from prospective clinical sequencing of 10,000 patients. Nat Med 2017, 23 (6), 703-713.

104. Rizvi, N. A.; Hellmann, M. D.; Snyder, A.; Kvistborg, P.; Makarov, V.; Havel, J. J.; Lee, W.; Yuan, J.; Wong, P.; Ho, T. S.; Miller, M. L.; Rekhtman, N.; Moreira, A. L.; Ibrahim, F.; Bruggeman, C.; Gasmi, B.; Zappasodi, R.; Maeda, Y.; Sander, C.; Garon, E. B.; Merghoub, T.; Wolchok, J. D.; Schumacher, T. N.; Chan, T. A., Mutational landscape determines sensitivity to PD-1 blockade in non-small cell lung cancer. Science 2015, 348 (6230), 124-8.

105. Van Allen, E. M.; Miao, D.; Schilling, B.; Shukla, S. A.; Blank, C.; Zimmer, L.; Sucker, A.; Hillen, U.; Foppen, M. H. G.; Goldinger, S. M.; Utikal, J.; Hassel, J. C.; Weide, B.; Kaehler, K. C.; Loquai, C.; Mohr, P.; Gutzmer, R.; Dummer, R.; Gabriel, S.; Wu, C. J.; Schadendorf, D.; Garraway, L. A., Genomic correlates of response to CTLA-4 blockade in metastatic melanoma. Science 2015, 350 (6257), 207-211.

106. Chan, T. A.; Yarchoan, M.; Jaffee, E.; Swanton, C.; Quezada, S. A.; Stenzinger, A.; Peters, S., Development of tumor mutation burden as an immunotherapy biomarker: utility for the oncology clinic. Ann Oncol 2019, 30 (1), 44-56.

107. Lawrence, M. S.; Stojanov, P.; Polak, P.; Kryukov, G. V.; Cibulskis, K.; Sivachenko, A.; Carter, S. L.; Stewart, C.; Mermel, C. H.; Roberts, S. A.; Kiezun, A.; Hammerman, P. S.; McKenna, A.; Drier, Y.; Zou, L.; Ramos, A. H.; Pugh, T. J.; Stransky, N.; Helman, E.; Kim, J.; Sougnez, C.; Ambrogio, L.; Nickerson, E.; Shefler, E.; Cortés, M. L.; Auclair, D.; Saksena, G.; Voet, D.; Noble, M.; DiCara, D.; Lin, P.; Lichtenstein, L.; Heiman, D. I.; Fennell, T.; Imielinski, M.; Hernandez, B.; Hodis, E.; Baca, S.; Dulak, A. M.; Lohr, J.; Landau, D. A.; Wu, C. J.; Melendez-Zajgla, J.; Hidalgo-Miranda, A.; Koren, A.; McCarroll, S. A.; Mora, J.; Crompton, B.; Onofrio, R.; Parkin, M.; Winckler, W.; Ardlie, K.; Gabriel, S. B.; Roberts, C. W. M.; Biegel, J. A.; Stegmaier, K.; Bass, A. J.; Garraway, L. A.; Meyerson, M.; Golub, T. R.; Gordenin, D. A.; Sunyaev, S.; Lander, E. S.; Getz, G., Mutational heterogeneity in cancer and the search for new cancer-associated genes. Nature 2013, 499 (7457), 214-218.

108. Barroso-Sousa, R.; Jain, E.; Cohen, O.; Kim, D.; Buendia-Buendia, J.; Winer, E.; Lin, N.; Tolaney, S. M.; Wagle, N., Prevalence and mutational determinants of high tumor mutation burden in breast cancer. Ann Oncol 2020, 31 (3), 387-394.

109. Mei, P.; Freitag, C. E.; Wei, L.; Zhang, Y.; Parwani, A. V.; Li, Z., High tumor mutation burden is associated with DNA damage repair gene mutation in breast carcinomas. Diagn Pathol 2020, 15 (1), 50.

110. Karn, T.; Denkert, C.; Weber, K. E.; Holtrich, U.; Hanusch, C.; Sinn, B. V.; Higgs, B. W.; Jank, P.; Sinn, H. P.; Huober, J.; Becker, C.; Blohmer, J. U.; Marmé, F.; Schmitt, W. D.; Wu, S.; van Mackelenbergh, M.; Müller, V.; Schem, C.; Stickeler, E.; Fasching, P. A.; 
Jackisch, C.; Untch, M.; Schneeweiss, A.; Loibl, S., Tumor mutational burden and immune infiltration as independent predictors of response to neoadjuvant immune checkpoint inhibition in early TNBC in GeparNuevo. Ann Oncol 2020, 31 (9), 1216-1222.

111. Karn, T.; Jiang, T.; Hatzis, C.; Sänger, N.; El-Balat, A.; Rody, A.; Holtrich, U.; Becker, S.; Bianchini, G.; Pusztai, L., Association Between Genomic Metrics and Immune Infiltration in Triple-Negative Breast Cancer. JAMA Oncol 2017, 3 (12), 1707-1711.

112. Huang, R. S. P.; Haberberger, J.; Severson, E.; Duncan, D. L.; Hemmerich, A.; Edgerly, C.; Ferguson, N. L.; Williams, E.; Elvin, J.; Vergilio, J. A.; Killian, J. K.; Lin, D. I.; Tse, J.; Hiemenz, M.; Owens, C.; Danziger, N.; Hegde, P. S.; Venstrom, J.; Alexander, B.; Ross, J. S.; Ramkissoon, S. H., A pan-cancer analysis of PD-L1 immunohistochemistry and gene amplification, tumor mutation burden and microsatellite instability in 48,782 cases. Mod Pathol 2020.

113. Barrett, M. T.; Lenkiewicz, E.; Malasi, S.; Basu, A.; Yearley, J. H.; Annamalai, L.; McCullough, A. E.; Kosiorek, H. E.; Narang, P.; Wilson Sayres, M. A.; Chen, M.; Anderson, K. S.; Pockaj, B. A., The association of genomic lesions and PD-1/PD-L1 expression in resected triple-negative breast cancers. Breast Cancer Res 2018, 20 (1), 71.

114. Chumsri, S.; Sokol, E. S.; Soyano-Muller, A. E.; Parrondo, R. D.; Reynolds, G. A.; Nassar, A.; Thompson, E. A., Durable Complete Response With Immune Checkpoint Inhibitor in Breast Cancer With High Tumor Mutational Burden and APOBEC Signature. J Natl Compr Canc Netw 2020, 18 (5), 517-521.

115. Voutsadakis, I. A., High Tumor Mutation Burden and Other Immunotherapy Response Predictors in Breast Cancers: Associations and Therapeutic Opportunities. Target Oncol 2020, $15(1), 127-138$.

116. Lan, H.; Bu, Q.; Zhuang, L.; Ren, S.; Yan, X.; Li, Y.; Yu, Q.; Shi, X.; Zhao, J.; Guo, $\mathrm{H}$.; Zhao, L., Frequency of homologous recombination-related gene mutations in breast cancer and their correlation with tumor mutation burden. Cancer Res 2020.

117. Angus, L.; Smid, M.; Wilting, S. M.; van Riet, J.; Van Hoeck, A.; Nguyen, L.; NikZainal, S.; Steenbruggen, T. G.; Tjan-Heijnen, V. C. G.; Labots, M.; van Riel, J.; Bloemendal, H. J.; Steeghs, N.; Lolkema, M. P.; Voest, E. E.; van de Werken, H. J. G.; Jager, A.; Cuppen, E.; Sleijfer, S.; Martens, J. W. M., The genomic landscape of metastatic breast cancer highlights changes in mutation and signature frequencies. Nat Genet 2019, 51 (10), 1450-1458. 118. Barroso-Sousa, R.; Keenan, T. E.; Pernas, S.; Exman, P.; Jain, E.; Garrido-Castro, A. C.; Hughes, M.; Bychkovsky, B.; Umeton, R.; Files, J. L.; Lindeman, N. I.; MacConaill, L. E.; Hodi, F. S.; Krop, I. E.; Dillon, D.; Winer, E. P.; Wagle, N.; Lin, N. U.; Mittendorf, E. A.; Van Allen, E. M.; Tolaney, S. M., Tumor Mutational Burden and PTEN Alterations as Molecular Correlates of Response to PD-1/L1 Blockade in Metastatic Triple-Negative Breast Cancer. Clin Cancer Res 2020, 26 (11), 2565-2572.

119. Zhang, X.; Zhao, W.; Wei, W.; You, Z.; Ou, X.; Sun, M.; Yin, Y.; Tang, X.; Zhao, Z.; Hu, C.; Liu, F.; Deng, J.; Mao, L.; Zhou, D.; Ren, Y.; Li, X.; Zhang, S.; Liu, C.; Geng, J.; Yao, G.; Song, B.; Liu, Y.; Li, D.; Jiang, Y.; Chen, Y.; Zhao, Y.; Yu, S.; Pang, D., Parallel Analyses of Somatic Mutations in Plasma Circulating Tumor DNA (ctDNA) and Matched Tumor Tissues in Early-Stage Breast Cancer. Clin Cancer Res 2019, 25 (21), 6546-6553.

120. Campesato, L. F.; Barroso-Sousa, R.; Jimenez, L.; Correa, B. R.; Sabbaga, J.; Hoff, P. M.; Reis, L. F.; Galante, P. A.; Camargo, A. A., Comprehensive cancer-gene panels can be used to estimate mutational load and predict clinical benefit to PD-1 blockade in clinical practice. Oncotarget 2015, 6 (33), 34221-7.

121. Hellmann, M. D.; Ciuleanu, T. E.; Pluzanski, A.; Lee, J. S.; Otterson, G. A.; AudigierValette, C.; Minenza, E.; Linardou, H.; Burgers, S.; Salman, P.; Borghaei, H.; Ramalingam, S. S.; Brahmer, J.; Reck, M.; O'Byrne, K. J.; Geese, W. J.; Green, G.; Chang, H.; Szustakowski, J.; Bhagavatheeswaran, P.; Healey, D.; Fu, Y.; Nathan, F.; Paz-Ares, L., 
Nivolumab plus Ipilimumab in Lung Cancer with a High Tumor Mutational Burden. N Engl J Med 2018, 378 (22), 2093-2104.

122. Goodman, A. M.; Kato, S.; Bazhenova, L.; Patel, S. P.; Frampton, G. M.; Miller, V.; Stephens, P. J.; Daniels, G. A.; Kurzrock, R., Tumor Mutational Burden as an Independent Predictor of Response to Immunotherapy in Diverse Cancers. Mol Cancer Ther 2017, 16 (11), 2598-2608.

123. Legrand, F. A.; Gandara, D. R.; Mariathasan, S.; Powles, T.; He, X.; Zhang, W.; Jhunjhunwala, S.; Nickles, D.; Bourgon, R.; Schleifman, E.; Paul, S. M.; Kadel, E. E.; Kowanetz, M.; Cummings, C.; Li, Y.; Fabrizio, D.; Peters, E.; Hegde, P. S.; Amler, L.; Shames, D. S., Association of high tissue TMB and atezolizumab efficacy across multiple tumor types. Journal of Clinical Oncology 2018, 36 (15_suppl), 12000-12000.

124. FDA approves pembrolizumab for adults and children with TMB-H solid tumors | FDA. https://www.fda.gov/drugs/drug-approvals-and-databases/fda-approves-pembrolizumab-adultsand-children-tmb-h-solid-tumors.

125. Samstein, R. M.; Lee, C. H.; Shoushtari, A. N.; Hellmann, M. D.; Shen, R.; Janjigian, Y. Y.; Barron, D. A.; Zehir, A.; Jordan, E. J.; Omuro, A.; Kaley, T. J.; Kendall, S. M.; Motzer, R. J.; Hakimi, A. A.; Voss, M. H.; Russo, P.; Rosenberg, J.; lyer, G.; Bochner, B. H.; Bajorin, D. F.; Al-Ahmadie, H. A.; Chaft, J. E.; Rudin, C. M.; Riely, G. J.; Baxi, S.; Ho, A. L.; Wong, R. J.; Pfister, D. G.; Wolchok, J. D.; Barker, C. A.; Gutin, P. H.; Brennan, C. W.; Tabar, V.; Mellinghoff, I. K.; DeAngelis, L. M.; Ariyan, C. E.; Lee, N.; Tap, W. D.; Gounder, M. M.; D'Angelo, S. P.; Saltz, L.; Stadler, Z. K.; Scher, H. I.; Baselga, J.; Razavi, P.; Klebanoff, C. A.; Yaeger, R.; Segal, N. H.; Ku, G. Y.; DeMatteo, R. P.; Ladanyi, M.; Rizvi, N. A.; Berger, M. F.; Riaz, N.; Solit, D. B.; Chan, T. A.; Morris, L. G. T., Tumor mutational load predicts survival after immunotherapy across multiple cancer types. Nat Genet 2019, 51 (2), 202-206.

126. Mosele, F.; Remon, J.; Mateo, J.; Westphalen, C. B.; Barlesi, F.; Lolkema, M. P.; Normanno, N.; Scarpa, A.; Robson, M.; Meric-Bernstam, F.; Wagle, N.; Stenzinger, A.; Bonastre, J.; Bayle, A.; Michiels, S.; Bièche, I.; Rouleau, E.; Jezdic, S.; Douillard, J. Y.; Reis-Filho, J. S.; Dienstmann, R.; André, F., Recommendations for the use of next-generation sequencing (NGS) for patients with metastatic cancers: a report from the ESMO Precision Medicine Working Group. Ann Oncol 2020.

127. Vigliar, E.; Malapelle, U.; Bono, F.; Fusco, N.; Cortinovis, D.; Valtorta, E.; Spyridon, A.; Bimbatti, M.; Zocchi, M.; Piva, C.; Gaudioso, G.; laccarino, A.; Morbini, P.; Pagni, F., The Reproducibility of the Immunohistochemical PD-L1 Testing in Non-Small-Cell Lung Cancer: A Multicentric Italian Experience. BioMed Research International 2019, 2019, 7.

128. Fumagalli, C.; Guerini-Rocco, E.; Vacirca, D.; Passaro, A.; Marinis, F.; Barberis, M., The immune profile of EGFR-mutated non-small-cell lung cancer at disease onset and progression after tyrosine kinase inhibitors therapy. Immunotherapy 2018, 10 (12), 1041-1045.

129. Hirsch, F. R.; McElhinny, A.; Stanforth, D.; Ranger-Moore, J.; Jansson, M.; Kulangara, K.; Richardson, W.; Towne, P.; Hanks, D.; Vennapusa, B.; Mistry, A.; Kalamegham, R.; Averbuch, S.; Novotny, J.; Rubin, E.; Emancipator, K.; McCaffery, I.; Williams, J. A.; Walker, J.; Longshore, J.; Tsao, M. S.; Kerr, K. M., PD-L1 Immunohistochemistry Assays for Lung Cancer: Results from Phase 1 of the Blueprint PD-L1 IHC Assay Comparison Project. J Thorac Oncol 2017, 12 (2), 208-222.

130. Scott, M.; Scorer, P.; Barker, C.; Al-Masri, H., Comparison of patient populations identified by different PD-L1 assays in in triple-negative breast cancer (TNBC). Annals of Oncology 2019, 30, iii4.

131. Schmid, P.; Adams, S.; Rugo, H. S.; Schneeweiss, A.; Barrios, C. H.; Iwata, H.; Diéras, V.; Hegg, R.; Im, S. A.; Shaw Wright, G.; Henschel, V.; Molinero, L.; Chui, S. Y.; Funke, R.; Husain, A.; Winer, E. P.; Loi, S.; Emens, L. A.; Investigators, I. T., Atezolizumab 
and Nab-Paclitaxel in Advanced Triple-Negative Breast Cancer. N Engl J Med 2018, 379 (22), 2108-2121.

132. https://www.fda.gov/drugs/drug-approvals-and-databases/fda-approves-atezolizumabpd-11-positive-unresectable-locally-advanced-or-metastatic-triple-negative.

133. NCCN Clinical Practice Guidelines in Oncology (NCCN Guidelines). Breast Cancer. NCCN Guidelines with NCCN Evidence Blocks ${ }^{\mathrm{TM}}$. Version 5.2020 - July 15, 2020. NCCN.org.

134. Cardoso, F.; Paluch-Shimon, S.; Senkus, E.; Curigliano, G.; Aapro, M. S.; André, F.; Barrios, C. H.; Bergh, J.; Bhattacharyya, G. S.; Biganzoli, L.; Boyle, F.; Cardoso, M. J.; Carey, L. A.; Cortés, J.; El Saghir, N. S.; Elzayat, M.; Eniu, A.; Fallowfield, L.; Francis, P. A.; Gelmon, K.; Gligorov, J.; Haidinger, R.; Harbeck, N.; Hu, X.; Kaufman, B.; Kaur, R.; Kiely, B. E.; Kim, S. B.; Lin, N. U.; Mertz, S. A.; Neciosup, S.; Offersen, B. V.; Ohno, S.; Pagani, O.; Prat, A.; Penault-Llorca, F.; Rugo, H. S.; Sledge, G. W.; Thomssen, C.; Vorobiof, D. A.; Wiseman, T.; Xu, B.; Norton, L.; Costa, A.; Winer, E. P., 5th ESO-ESMO international consensus guidelines for advanced breast cancer (ABC 5). Ann Oncol 2020.

135. VENTANA PD-L1 (SP142) Assay Interpretation Guide for Triple-Negative Breast Carcinoma (TNBC). Ventana. Roche.

136. Marcus, L.; Lemery, S. J.; Keegan, P.; Pazdur, R., FDA Approval Summary: Pembrolizumab for the Treatment of Microsatellite Instability-High Solid Tumors. Clin Cancer Res 2019, 25 (13), 3753-3758.

137. Loughrey, M. A.-O.; McGrath, J.; Coleman, H. G.; Bankhead, P. A.-O.; Maxwell, P.; McGready, C.; Bingham, V.; Humphries, M. A.-O.; Craig, S. G.; McQuaid, S.; Salto-Tellez, M.; James, J. A.-O., Identifying mismatch repair-deficient colon cancer: near-perfect concordance between immunohistochemistry and microsatellite instability testing in a large, population-based series. LID - 10.1111/his.14233 [doi]. (1365-2559 (Electronic)).

138. Luchini, C.; Bibeau, F.; Ligtenberg, M. J. L.; Singh, N.; Nottegar, A.; Bosse, T.; Miller, R.; Riaz, N.; Douillard, J. Y.; Andre, F.; Scarpa, A., ESMO recommendations on microsatellite instability testing for immunotherapy in cancer, and its relationship with PD-1/PD-L1 expression and tumour mutational burden: a systematic review-based approach. Ann Oncol 2019, 30 (8), 1232-1243.

139. Fumagalli, C.; Casadio, C.; Barberis, M.; Guarize, J.; Guerini-Rocco, E., Letter to the Editor. Clin Lung Cancer 2018, 19 (4), e439-e440.

140. Agrawal, L.; Engel, K. B.; Greytak, S. R.; Moore, H. M., Understanding preanalytical variables and their effects on clinical biomarkers of oncology and immunotherapy. Semin Cancer Biol 2018, 52 (Pt 2), 26-38.

141. Rolfo, C.; Mack, P. C.; Scagliotti, G. V.; Baas, P.; Barlesi, F.; Bivona, T. G.; Herbst, R. S.; Mok, T. S.; Peled, N.; Pirker, R.; Raez, L. E.; Reck, M.; Riess, J. W.; Sequist, L. V.; Shepherd, F. A.; Sholl, L. M.; Tan, D. S. W.; Wakelee, H. A.; Wistuba, I. I.; Wynes, M. W.; Carbone, D. P.; Hirsch, F. R.; Gandara, D. R., Liquid Biopsy for Advanced Non-Small Cell Lung Cancer (NSCLC): A Statement Paper from the IASLC. $J$ Thorac Oncol 2018, 13 (9), 12481268.

142. Gandara, D. R.; Paul, S. M.; Kowanetz, M.; Schleifman, E.; Zou, W.; Li, Y.; Rittmeyer, A.; Fehrenbacher, L.; Otto, G.; Malboeuf, C.; Lieber, D. S.; Lipson, D.; Silterra, J.; Amler, L.; Riehl, T.; Cummings, C. A.; Hegde, P. S.; Sandler, A.; Ballinger, M.; Fabrizio, D.; Mok, T.; Shames, D. S., Blood-based tumor mutational burden as a predictor of clinical benefit in non-small-cell lung cancer patients treated with atezolizumab. Nat Med 2018, 24 (9), 14411448.

143. Georgiadis, A.; Durham, J. N.; Keefer, L. A.; Bartlett, B. R.; Zielonka, M.; Murphy, D.; White, J. R.; Lu, S.; Verner, E. L.; Ruan, F.; Riley, D.; Anders, R. A.; Gedvilaite, E.; Angiuoli, S.; Jones, S.; Velculescu, V. E.; Le, D. T.; Diaz, L. A.; Sausen, M., Noninvasive Detection of Microsatellite Instability and High Tumor Mutation Burden in Cancer Patients Treated with PD-1 Blockade. Clin Cancer Res 2019, 25 (23), 7024-7034. 
144. Hofman, P.; Heeke, S.; Alix-Panabières, C.; Pantel, K., Liquid biopsy in the era of immuno-oncology: is it ready for prime-time use for cancer patients? Ann Oncol 2019, 30 (9), 1448-1459.

145. Bertucci, F.; Ng, C. K. Y.; Patsouris, A.; Droin, N.; Piscuoglio, S.; Carbuccia, N.; Soria, J. C.; Dien, A. T.; Adnani, Y.; Kamal, M.; Garnier, S.; Meurice, G.; Jimenez, M.; Dogan, S.; Verret, B.; Chaffanet, M.; Bachelot, T.; Campone, M.; Lefeuvre, C.; Bonnefoi, H.; Dalenc, F.; Jacquet, A.; De Filippo, M. R.; Babbar, N.; Birnbaum, D.; Filleron, T.; Le Tourneau, C.; André, F., Genomic characterization of metastatic breast cancers. Nature 2019, 569 (7757), 560-564.

146. Jiang, W.; Chan, C. K.; Weissman, I. L.; Kim, B. Y. S.; Hahn, S. M., Immune Priming of the Tumor Microenvironment by Radiation. Trends Cancer 2016, 2 (11), 638-645.

147. Golden, E. B.; Demaria, S.; Schiff, P. B.; Chachoua, A.; Formenti, S. C., An abscopal response to radiation and ipilimumab in a patient with metastatic non-small cell lung cancer. Cancer Immunol Res 2013, 1 (6), 365-72.

148. Solinas, C.; Marcoux, D.; Garaud, S.; Vitória, J. R.; Van den Eynden, G.; de Wind, A.; De Silva, P.; Boisson, A.; Craciun, L.; Larsimont, D.; Piccart-Gebhart, M.; Detours, V.; t'Kint de Roodenbeke, D.; Willard-Gallo, K., BRCA gene mutations do not shape the extent and organization of tumor infiltrating lymphocytes in triple negative breast cancer. Cancer Lett 2019, 450, 88-97.

149. Sønderstrup, I. M. H.; Jensen, M. B.; Ejlertsen, B.; Eriksen, J. O.; Gerdes, A. M.; Kruse, T. A.; Larsen, M. J.; Thomassen, M.; Laenkholm, A. V., Evaluation of tumor-infiltrating lymphocytes and association with prognosis in BRCA-mutated breast cancer. Acta Oncol 2019, 58 (3), 363-370.

150. Criscitiello, C.; Curigliano, G., Tumour infiltrating lymphocytes and correlation with response to intensified platinum-based chemotherapy in BRCA-like tumours. Eur $J$ Cancer 2020, 127, 236-239.

151. Domchek, S. M.; Postel-Vinay, S.; Im, S. A.; Park, Y. H.; Delord, J. P.; Italiano, A.; Alexandre, J.; You, B.; Bastian, S.; Krebs, M. G.; Wang, D.; Waqar, S. N.; Lanasa, M.; Rhee, J.; Gao, H.; Rocher-Ros, V.; Jones, E. V.; Gulati, S.; Coenen-Stass, A.; Kozarewa, I.; Lai, Z.; Angell, H. K.; Opincar, L.; Herbolsheimer, P.; Kaufman, B., Olaparib and durvalumab in patients with germline BRCA-mutated metastatic breast cancer (MEDIOLA): an open-label, multicentre, phase 1/2, basket study. Lancet Oncol 2020, 21 (9), 1155-1164.

152. Vinayak, S.; Tolaney, S. M.; Schwartzberg, L.; Mita, M.; McCann, G.; Tan, A. R.; Wahner-Hendrickson, A. E.; Forero, A.; Anders, C.; Wulf, G. M.; Dillon, P.; Lynce, F.; Zarwan, C.; Erban, J. K.; Zhou, Y.; Buerstatte, N.; Graham, J. R.; Arora, S.; Dezube, B. J.; Telli, M. L., Open-Label Clinical Trial of Niraparib Combined With Pembrolizumab for Treatment of Advanced or Metastatic Triple-Negative Breast Cancer. JAMA Oncol 2019, 5 (8), 1132-40.

153. Brignone, C.; Gutierrez, M.; Mefti, F.; Brain, E.; Jarcau, R.; Cvitkovic, F.; Bousetta, N.; Medioni, J.; Gligorov, J.; Grygar, C.; Marcu, M.; Triebel, F., First-line chemoimmunotherapy in metastatic breast carcinoma: combination of paclitaxel and IMP321 (LAG-3lg) enhances immune responses and antitumor activity. J Trans/ Med 2010, 8, 71.

154. Hong, D. S.; Schoffski, P.; Calvo, A.; Sarantopoulos, J.; Ochoa De Olza, M.; Carvajal, R. D.; Prawira, A.; Kyi, C.; Esaki, T.; Akerley, W. L.; De Braud, F. G.; Hui, R.; Zhang, T.; Soo, R. A.; Maur, M.; Weickhardt, A. J.; Roy Chowdhury, N.; Sabatos-Peyton, C.; Kwak, E. L.; Tan, D. S.-W., Phase I/II study of LAG525 \pm spartalizumab (PDR001) in patients (pts) with advanced malignancies. Journal of Clinical Oncology 2018, 36 (15_suppl), 3012-3012.

155. Tarantino, P.; Gandini, S.; Trapani, D.; Criscitiello, C.; Curigliano, G., Immunotherapy addition to neoadjuvant chemotherapy for early triple negative breast cancer: a systematic review and meta-analysis of randomized clinical trials. Critical Reviews in Oncology/Hematology 2021, 103223. 
156. Vasen, H. F.; Blanco, I.; Aktan-Collan, K.; Gopie, J. P.; Alonso, A.; Aretz, S.; Bernstein, I.; Bertario, L.; Burn, J.; Capella, G.; Colas, C.; Engel, C.; Frayling, I. M.; Genuardi, M.; Heinimann, K.; Hes, F. J.; Hodgson, S. V.; Karagiannis, J. A.; Lalloo, F.; Lindblom, A.; Mecklin, J. P.; Møller, P.; Myrhoj, T.; Nagengast, F. M.; Parc, Y.; Ponz de Leon, M.; Renkonen-Sinisalo, L.; Sampson, J. R.; Stormorken, A.; Sijmons, R. H.; Tejpar, S.; Thomas, H. J.; Rahner, N.; Wijnen, J. T.; Järvinen, H. J.; Möslein, G., Revised guidelines for the clinical management of Lynch syndrome (HNPCC): recommendations by a group of European experts. Gut 2013, 62 (6), 812-23. 